\title{
FALLOS DE MERCADO Y SEGURO DE PARO EN ESPAÑA ANTES DE 1936*
}

SERGIO ESPUELAS

Centre d'Estudis 'Antoni de Capmany' d'Economia i Història Econòmica ${ }^{a}$

Market Failures and Unemployment Insurance in Spain before 1936

\begin{abstract}
Before 1936, private insurance against unemployment was mostly run by trade unions. Commercial companies, meanwhile, did not penetrate into this insurance branch, which is probably due to the advantages that trade unions had when dealing with adverse selection and moral hazard problems. Nevertheless, union-based unemployment insurance reached a lower level of development than other private social insurance schemes, like sickness insurance, perhaps because of the financial difficulties that economic crisis involved for unemployment funds. Also, unemployment insurance spread specially among urban and high-wage workers, although coverage rates in Spain were below those of other European countries with higher income levels. However, even in the latter private coverage against unemployment did not reach $10 \%$ of the working population. As in other European countries, Spanish unemployment union-funds implemented strict economic incentives to deal with moral hazard, but precisely this hindered the spreading of private unemployment insurance.

Keywords: unemployment insurance, market imperfections, economic history

JEL Classification: J65, D43, N34

* Received 23 April 2013. Accepted 25 September 2013. Este trabajo ha contado con el apoyo del proyecto del MEC (ECO2009-13331-C02-02) y de la Xarxa d'Economia i Polítiques Públiques dependiente de la Generalitat de Cataluña. Una versión previa de este trabajo se presentó en el X Congreso de la AEHE, (Carmona, 2011). Agradezco a todos los participantes, y muy especialmente a Alfonso Herranz, Jerònia Pons, Margarita Vilar y tres evaluadores anónimos por sus útiles observaciones, comentarios y sugerencias. Como siempre, cualquier error es exclusivamente responsabilidad del autor.

a Departament d'Història i Institucions Econòmiques, Facultat d'Economia i Empresa, Universitat de Barcelona, Edifici Principal, Torre 2 - 4a planta, Av. Diagonal, 690 - 08034 Barcelona. Correo-e: sergio.espuelas@ub.edu.
\end{abstract}




\section{RESUMEN}

Antes de 1936, el seguro privado contra el paro estuvo básicamente a cargo de los sindicatos, mientras que las compañías comerciales no se adentraron en esta rama del seguro, lo que se podría explicar por las ventajas que los primeros tenían a la hora de combatir los problemas de selección adversa y riesgo moral. No obstante, el seguro de paro de base sindical alcanzó menos desarrollo que otros seguros sociales privados, como el de enfermedad, quizás por las dificultades financieras que implicaban las crisis económicas. Además, el seguro de paro se difundió sobre todo entre los trabajadores urbanos con salarios elevados. En España, sin embargo, las tasas de cobertura se mantuvieron por debajo de las de otros países europeos que tenían niveles de renta más elevados, aunque incluso en estos la cobertura privada contra el paro no llegaba al 10\% de la población activa. En España, como en otros países europeos, los fondos sindicales contra el paro introdujeron estrictos incentivos económicos para combatir los problemas de riesgo moral, pero eso precisamente dificultó la difusión del seguro privado de paro.

Palabras clave: seguro de desempleo, imperfecciones del mercado, historia económica

\section{INTRODUCCIÓN}

Antes de la aparición del Estado del bienestar, ya existían mecanismos no estatales de protección social, que normalmente estaban a cargo de mutuas y sindicatos, o incluso compañías privadas de seguros que complementaban la escasa protección social ofrecida por el Estado y las redes familiares. En el caso de las sociedades de socorros mutuos, estas se fueron desarrollando a lo largo del siglo XIX, en buena medida, como respuesta a las necesidades originadas por el avance de la industrialización y a la pasividad del Estado en materia de política social, hasta convertirse en la que seguramente fue la principal forma de protección social de los trabajadores en el siglo XIX ${ }^{1}$. Posteriormente, desde finales del siglo XIX, y sobre todo en las primeras décadas del siglo XX, los sindicatos de trabajadores empezaron a ofrecer seguros sociales a sus afiliados como un servicio adicional a la actividad estrictamente sindical, dando lugar a la llamada «base múltiple», que en muchas ocasiones les permitió aumentar su afiliación y hacerla más estable ${ }^{2}$.

\footnotetext{
1 Castillo (1994) y Vilar (2010).
}

2 González Gómez (1994). 
Sin embargo, a pesar de que, como ha señalado van Leeuwen (2007), el estudio de las mutuas y los fondos sindicales ha florecido en las últimas décadas, rara vez han sido estudiadas como entidades aseguradoras que en buena medida estaban expuestas a los mismos fallos de mercado que afectan a cualquier seguro privado, ya sea de carácter mutualista, sindical o comercial.

El objetivo de este trabajo es analizar la situación de la protección privada contra el paro en España antes de 1936 (entendida como la protección no estatal a cargo de mutuas, sindicatos y compañías comerciales) a la luz de las teorías actuales sobre los fallos de mercado. Para ello se ha intentado cuantificar (en la medida de lo posible) cuál era el alcance de la cobertura privada contra el paro antes de 1936, qué tipo de instituciones ofrecían el seguro, quiénes eran sus beneficiarios y cuáles eran las características de las prestaciones que estos recibían. También se ha tratado de comparar la situación en España con la de otros países europeos; para finalmente ofrecer una interpretación sobre la situación en la que se encontraba el seguro de paro a partir de la teoría sobre los fallos del mercado.

Para sentar las bases de la interpretación que se ofrece a lo largo del trabajo, en el próximo apartado se resumen brevemente los principales fallos de mercado que afectan al seguro de desempleo y las principales soluciones que se pueden aplicar para corregirlos. En el tercer apartado, se ofrece una aproximación cuantitativa sobre el alcance que tuvo el seguro privado contra el paro en España antes de 1936, se analiza qué tipo de entidades ofrecían el seguro de desempleo (sindicatos, mutuas y compañías comerciales), y se comparan los niveles de protección con los de otros riesgos sociales. En el cuarto apartado, se ha tratado de identificar qué tipo de trabajadores eran los beneficiarios del seguro privado contra el paro, y en el quinto se analiza el funcionamiento de las asociaciones que cubrían el riesgo de paro y la generosidad de sus prestaciones, comparando la situación con la de otros países europeos. Finalmente, en el sexto apartado se resumen las principales conclusiones.

\section{FALLOS DE MERCADO}

Los principales fallos de mercado que afectan al seguro de desempleo (independientemente de si está organizado por compañías privadas, mutuas o sindicatos) son tres: los problemas de selección adversa y riesgo moral, que son problemas de información asimétrica, y los problemas derivados del hecho de que la probabilidad del riesgo de paro está, en ocasiones, próxima a la unidad ${ }^{3}$. Los problemas de selección adversa surgen cuando los asegurados son capaces de ocultar a los aseguradores información sobre el riesgo que afrontan; de

\footnotetext{
${ }^{3}$ Barr (1992).
} 
forma que estos no pueden distinguir entre «buenos» $\mathrm{y}$ «malos» riesgos. En esta situación, el asegurador solo puede fijar primas basadas en el riesgo medio, lo que beneficia a los «malos» riesgos, que pagan primas inferiores a las que pagarían en un mercado competitivo, y perjudica a los «buenos» riesgos, que pagan primas superiores. Como resultado, los «buenos» riesgos tienen incentivos para no asegurarse (y no subvencionar a los malos riesgos), y ello a su vez encarece el seguro para los «malos» riesgos; de forma que la cobertura final será más baja de lo que sería si el asegurador pudiese distinguir perfectamente entre «buenos» $\mathrm{y}$ «malos» riesgos. Una forma de solucionar estos problemas es haciendo obligatorio el seguro, para que los aseguradores puedan fijar primas acordes al riesgo medio ${ }^{4}$. Una solución parcial consiste en mejorar las técnicas de selección de riesgos, estableciendo, por ejemplo, periodos de carencia (pagando primas sin derecho a indemnización) para que los «malos» riesgos salgan a la luz o, sencillamente, disuadirlos ${ }^{5}$.

En cuanto a los problemas de riesgo moral, estos aparecen cuando la persona asegurada tiene capacidad para influir en la probabilidad de que el riesgo ocurra, sin que el asegurador tenga conocimiento de ello. En el caso del seguro de desempleo, por ejemplo, puede ocurrir que los asegurados se esfuercen menos por conservar su empleo y, sobre todo, puede hacer que sean menos diligentes en la búsqueda de un nuevo empleo. Según Barr (1992), los problemas de riesgo moral son, de hecho, mayores en el caso del seguro de desempleo que en la mayoría de riesgos sociales, ya que, a diferencia de la enfermedad (donde también puede haber problemas de riesgo moral), no existen síntomas externos, más o menos claros, que un médico pueda diagnosticar y que permitan a los aseguradores saber si el desempleo es involuntario o no. Estos problemas no hacen el seguro completamente inviable, pero dan lugar a ineficiencias. Concretamente, la prima de riesgo será más alta que en un mercado con información perfecta donde el asegurador pudiese diferenciar perfectamente entre desempleo voluntario e involuntario. Los problemas de riesgo moral no se pueden solucionar por completo, pero se pueden atenuar. Una forma es seguir de cerca el comportamiento de los asegurados. La inspección médica obligatoria en el caso del seguro de enfermedad es un ejemplo en ese sentido. En el caso del seguro de desempleo, es típico obligar a los parados a presentarse periódicamente en una oficina de colocación. El inconveniente de estas medidas es que aumentan los costes. Otra forma de lidiar con los problemas de riesgo moral consiste en imponer sobre los asegurados una parte del coste que implica el desempleo, lo que se consigue fijando prestaciones inferiores al salario habitual y de duración limitada. Esta última medida, de hecho, implica que, a partir de un cierto momento, el coste del desempleo lo soporta por completo el asegurado.

\footnotetext{
${ }^{4}$ Íbid.

${ }^{5}$ Van Leeuwen (1997).
} 
Por último, el tercer problema que dificulta la viabilidad del seguro privado de paro es el hecho de que, en determinadas ocasiones, la probabilidad de pasar a estar desempleado (y/o de permanecer en el paro) es muy alta. En estos casos, la prima de riesgo es tan alta que es casi igual a la perdida que se pretende asegurar y, por tanto, no hay demanda para el seguro ${ }^{6}$. Esto explica, por ejemplo, por qué los trabajadores que tienen probabilidades muy altas de caer en el paro (que normalmente son los menos cualificados y con salarios más bajos) difícilmente podrían asegurarse en un mercado privado, ya que las primas serían demasiado altas. Esto también explica por qué el seguro es inviable en caso de depresiones cíclicas (que aumentan el riesgo de paro y por tanto las primas para todos los trabajadores) o de desempleo estacional (en el que el paro deja de ser un riesgo para convertirse en casi una certeza). En todos estos casos, el seguro solo es viable con financiación pública. El objetivo de los próximos apartados es analizar en qué medida estos fallos de mercado nos ayudan a interpretar la situación en la que efectivamente se encontraba la protección privada contra el paro en España antes de 1936.

\section{LA PROTECCIÓN PRIVADA CONTRA EL PARO ANTES DE 1936}

Como sucedería también en otros países europeos, en la España de principios del siglo XX el desempleo constituyó un grave problema que se convertiría en fuente de inestabilidad política. El paro agrícola fue particularmente importante en España, especialmente en las zonas latifundistas, aunque el paro industrial y urbano fue ganando protagonismo a medida que avanzaba el proceso de industrialización. Las soluciones al problema del desempleo pasaron por opciones muy diferentes. Una de ellas fueron las migraciones. En Europa, por ejemplo, las migraciones masivas al exterior aumentaron notoriamente tras la crisis agraria de finales del siglo XIX ${ }^{7}$. De forma similar, las migraciones internas actuaron como válvula escape frente al problema del paro. Las migraciones temporales, de hecho, (basadas tanto en movimientos dentro del propio sector agrario como entre áreas rurales y urbanas) fueron considerables antes del gran éxodo rural de la década de 1960 y actuaron como una respuesta a la estacionalidad de la producción agrícola ${ }^{8}$. Por otro lado, en la agricultura también era habitual la utilización de contratos de larga duración para reducir la presión del paro estacional y estabilizar los ingresos entre las temporadas altas y bajas. Con estos contratos se pretendía dar a los trabajadores incentivos para desarrollar un trabajo de calidad; y también podían utilizarse como política paternalista en momentos de conflictividad social, para ganarse la lealtad de una parte

\footnotetext{
6 Barr (1992).

7 Cf. Sánchez-Alonso (2000).

8 Silvestre (2007).
} 
de los trabajadores, como parece que sucedió en Campiña de Córdoba entre 1888 y $1930^{9}$.

En el caso de la industria, desde finales del siglo XIX también se dieron pactos entre empresarios y trabajadores para repartir el trabajo (work sharing) y mantener el empleo en periodos de crisis cíclicas; una práctica que además permitía a las empresas retener el capital humano ${ }^{10}$. Durante la crisis de la década de 1930, esta práctica se difundió por muchas bases de trabajo que establecieron clausulas para repartir el trabajo entre la plantilla en caso de "falta de trabajo", aunque no siempre se hizo extensivo a las mujeres. En algunas bases de trabajo, especialmente agrícolas, se prohibía incluso la contratación de mujeres mientras existiese paro masculino ${ }^{11}$. Los poderes públicos, por su parte, acostumbraban a invertir en obras públicas contra el paro en periodos de crisis cíclica o estacional. Esta era una medida que había sido tradicionalmente utilizada en la agricultura pero que también se aplicó para combatir el paro industrial o urbano y fue ampliamente utilizada durante la crisis de la década de 1930. También durante los años de la Segunda República, el Gobierno intentó solucionar el problema del paro estacional agrícola mediante los polémicos decretos del laboreo forzoso, que pretendía evitar que los propietarios dejasen sin cultivar sus tierras, y de los términos municipales, que obligaba a los propietarios a contratar primero a los trabajadores residentes en el municipio ${ }^{12}$.

A finales del siglo XIX, y sobre todo después de la primera guerra mundial, varios países europeos empezaron a implantar seguros de desempleo y a crear oficinas públicas de colocación. En España, el primer sistema público de colocación no se creó hasta 1931. Antes de esa fecha, se promocionó la creación de oficinas de colocación en determinados organismos públicos, como las cámaras agrícolas y de comercio (reales decretos de 14 de noviembre de 1890 y 12 de junio de 1919), y en los años veinte se concedieron subvenciones a bolsas de trabajo privadas, pero en ningún caso se creó un sistema público de alcance nacional. En cuanto al seguro de desempleo, el Gobierno tomó diversas medidas antes de 1931, pero la mayoría no pasaron de meros proyectos. En 1910, por ejemplo, el Gobierno encargó al Instituto Nacional de Previsión (INP) un anteproyecto de ley para crear un seguro de paro, pero no llegó a materializarse. En mayo de 1918, en medio del clima de conflictividad social que caracterizó ese periodo, el Gobierno aprobó un subsidio de paro restringido a la industria textil indemnizando a los trabajadores por los días de paro provocados por «las dificultades y limitaciones en la importación de algodón en rama». Esta medida sí llegó a aplicarse, pero fue retirada poco después, en marzo de 1919, cuando el Gobierno liberal del conde de Romanones aprobó un seguro de

\footnotetext{
9 Carmona y Simpson (2003).

10 Domenech (2008).

11 Bengoechea y Borderías (2010) y Espuny (2010).

12 Malefakis (1970).
} 
desempleo basado en el modelo de Gante. Dicho sistema consistía en subvencionar a los sindicatos y asociaciones que cubrían el riesgo de paro, pero no llegó a aplicarse por falta de dotación presupuestaria ${ }^{13}$.

En la convulsa década de 1920, el Gobierno volvió a emprender algunas iniciativas. En la Ley de Presupuestos de 1922 incluyó una partida creando un Fondo de Paro para subvencionar a las asociaciones que practicaban el seguro de paro; pero, como se verá más adelante, se destinaron muy pocos recursos. Y poco después, en 1923, el ministro de Trabajo presentó un proyecto de seguro de paro obligatorio que tampoco se aprobó debido al golpe de Estado de Primo de Rivera. Como resultado, el seguro de desempleo no se introdujo en España hasta mayo de 1931, cuando se creó un sistema basado en el modelo de Gante. No obstante, esta medida tuvo un alcance muy limitado (en 1936, la tasa de cobertura apenas superaba el 1\% de la población activa). Las causas de este fracaso son diversas, pero la falta de una amplia red de sindicatos con tradición aseguradora a la que poder subvencionar desde el Estado, seguramente fue determinante en ese sentido ${ }^{14}$. El objetivo de los siguientes apartados es, precisamente, analizar la evolución del seguro privado de paro antes de 1936.

\subsection{La situación alrededor de 1914}

Las primeras sociedades de socorros mutuos aparecieron en España tras la Real Orden de 28 de febrero de 1839, que reconoció el derecho de libre asociación de los trabajadores para auxiliarse mutuamente. Muchas de estas mutuas, sin embargo, tenían su origen en antiguos gremios extinguidos que a lo largo del siglo XIX se fueron desarrollando bajo esta nueva forma legal hasta convertirse en la que, seguramente, era la principal forma de protección social que tenían los trabajadores a su alcance, al margen de la protección que ofrecían las redes familiares ${ }^{15}$. Las compañías mercantiles, por su parte, también podían cubrir algunos riesgos sociales. Sin embargo, estas se fueron desarrollando con dificultad a lo largo del siglo XIX, ya que no fueron reguladas hasta 1908, cuando empezaron a crecer con mayor dinamismo gracias a la consolidación de un marco legal estable ${ }^{16}$. No obstante, sus actividades tendieron a concentrarse en ramos como el seguro de vida, de incendios o de transporte, por poner algunos ejemplos; mientras que en el área de los seguros de carácter social, las sociedades mutuas tuvieron más protagonismo que las compañías comerciales ${ }^{17}$.

\footnotetext{
13 García González (2010).

14 Espuelas (2010).

15 Castillo (1994) y Vilar (2010).

16 Pons (2002). Sobre la evolución del sector asegurador, véanse también Frax y Matilla (1996) y Pons y Pons (2010).

17 Pons y Vilar (2011).
} 
En lo que se refiere al desempleo, antes de la guerra civil la protección privada estuvo casi exclusivamente a cargo de los sindicatos y asociaciones obreras, mientras que las compañías mercantiles desempeñaron un papel minoritario (si es que tuvieron alguno). En 1914, el INP encargó a Francisco González y Ricardo Oyuelos un estudio que debía servir como anteproyecto de ley para crear un seguro de paro ${ }^{18}$. González y Oyuelos analizaron los mecanismos de lucha contra el paro que se habían ensayado en diversos países europeos y estudiaron detalladamente la situación del caso español, recabando, entre otras cosas, información sobre el alcance de la protección privada contra el paro en España alrededor de 1914. Esta es, de hecho, la primera fuente de información oficial que existe en ese sentido y ofrece cifras desagregadas por provincias sobre el número de sindicatos y asociaciones obreras que cubrían el riesgo de paro y sobre el número de asegurados que tenían. La información se basaba a su vez en las estadísticas del Instituto de Reformas Sociales (IRS), pero como ha señalado Vilar (2010), las cifras que se desprenden de estas estadísticas están seguramente sesgadas a la baja, lo que se explica tanto por las propias deficiencias de la administración española como por la ocultación deliberada por parte de las organizaciones obreras, que en ocasiones desconfiaban de las instituciones estatales. Dicho informe debe considerarse, por tanto, como una aproximación razonable (y en todo caso una de las pocas que existen), pero no como una descripción fiel de la realidad.

A lo largo del estudio no se menciona en ningún momento la existencia de asociaciones mercantiles, lo que hace suponer que (en caso de existir) debieron tener muy poca importancia. Asimismo, tras la entrada en vigor de la ley de Seguros Privados de 1908, la Dirección General de Seguros publicó, periódicamente, estadísticas sobre la evolución de dicho sector ${ }^{19}$. La desagregación más habitual distinguía entre los ramos de vida, tontinas, chatelusianas, incendios, ganados, accidentes (colectivos e individuales), enfermedades, cristales, y otros ramos; pero el riesgo de paro no se mencionaba. Por supuesto, no se puede descartar la posibilidad de que el epígrafe «otros» incluyese alguna compañía mercantil que cubriese el riesgo de paro, pero nuevamente todo parece indicar que, si existieron, tuvieron una importancia muy minoritaria.

Esta no parece, sin embargo, una característica exclusiva del caso español. En Holanda, la cobertura privada contra el paro también estaba casi exclusivamente limitada a los sindicatos, junto con un reducido número de mutuas; mientras que las compañías mercantiles se mantuvieron al margen de este sector ${ }^{20}$. Asimismo, los estudios de Beveridge (1989 [1944]) o Harris

${ }_{18}$ El Gobierno se lo había encargado a su vez al INP mediante real decreto de 5 de marzo de 1910.

19 Resúmenes de estas estadísticas pueden encontrarse en los Anuarios Estadísticos de España.

${ }^{20}$ Van Leeuwen (2007). 
(2004) sobre el alcance del seguro privado contra el paro en Gran Bretaña, o los de Alber (1981) sobre los países de la Europa occidental, se centran en el papel de los sindicatos, lo que de alguna manera revela que las compañías mercantiles tuvieron un papel marginal. Es difícil precisar las causas de este fenómeno, pero, como sugiere van Leeuwen (1997) para el caso holandés, posiblemente se deba a las ventajas que los sindicatos tenían frente a las compañías mercantiles a la hora de controlar los problemas de riesgo moral (que, como se vio antes, consistían básicamente en el abandono voluntario del trabajo y la pasividad en la búsqueda de empleo).

En el caso del seguro de enfermedad, por ejemplo, las entidades aseguradoras debían recurrir a un médico especialista para evitar que los asegurados fingiesen estar enfermos; y no hay ningún motivo para pensar que los fondos sindicales tuviesen en ese sentido ninguna ventaja sobre las compañías comerciales. En el caso del seguro de desempleo, en cambio, no existen síntomas externos que un especialista pueda diagnosticar. Por tanto, es necesario tener información sobre el mercado de trabajo y sobre la actitud de los desempleados en la búsqueda de empleo para determinar si el paro es voluntario o no. En ese sentido parece que los sindicatos tenían más capacidad para obtener información que las compañías comerciales, aunque seguramente también era imperfecta. Es posible que los miembros de los sindicatos pudiesen saber (en mayor medida que una compañía privada) si un trabajador había sido despedido o si se había marchado voluntariamente, o si existía algún puesto vacante que un parado había rechazado. De hecho, los reformistas sociales de la época, que eran partidarios del modelo de Gante, estaban convencidos de que «los miembros del sindicato o sociedad serán inspectores celosísimos, en su propio interés, de las causas que motiven el paro de sus compañeros» ${ }^{21}$.

De hecho, en los sectores donde los problemas de riesgo moral no eran tan intensos, o los sindicatos no tenían ninguna ventaja aparente para controlarlos, la presencia de mutuas y compañías comerciales era mucho mayor que en el caso del desempleo, lo que de alguna manera vendría a confirmar la hipótesis anterior. Los seguros de enfermedad y los servicios funerarios son, seguramente, el mejor ejemplo de ello. Ambos seguros eran ofrecidos por los sindicatos dentro del sistema de «base múltiple» y en ambos casos los problemas de riesgo moral son menores que en el seguro del desempleo. En el caso de la enfermedad, por ejemplo, ya se ha dicho que existen síntomas externos que puede diagnosticar un médico, al que pueden recurrir tanto las compañías comerciales como los fondos sindicales. En el caso de los servicios funerarios, los problemas de riesgo moral son, de hecho, mucho menores porque fingir la muerte es muy difícil y provocarla tiene (obviamente) un elevado coste para el asegurado. En ambos tipos de seguros, la presencia de compañías comerciales y, sobre todo, de mutuas fue mucho mayor que en el caso del seguro de paro. Según el registro oficial creado al

${ }^{21}$ González y Oyuelos (1914, p. 267). 
CUADRO 1

PROTECCIÓN PRIVADA CONTRA EL PARO EN ESPAÑA (1914)

\begin{tabular}{|l|c|c|}
\hline & $\begin{array}{c}\text { Número de } \\
\text { asociaciones }\end{array}$ & Asegurados \\
\hline Prestaciones en metálico & 117 & 14.393 \\
Exención de cotización & - & 62.450 \\
Servicio de colocación o registro de parados & - & 43.583 \\
Total & 587 & 84.415 \\
\hline
\end{tabular}

Fuente: González y Oyuelos (1914).

Nota: La suma de asegurados de las asociaciones que ofrecían prestaciones en metálico, eximían de cotización o tenían servicio de colocación no coinciden con el total porque había asociaciones que ofrecían simultáneamente varios de estos servicios.

amparo de la ley de seguros de 1908, en 1912 había 32 entidades operando en el sector de los seguros de enfermedad y decesos (en su mayoría, compañías comerciales; aunque también había algunas mutuas). En 1935, su número había ascendido a $75 \mathrm{y}$, entre ellas, se encontraban algunas que posteriormente se transformarían en importantes compañías generales como Santa Lucía o El Ocaso. A esto habría que sumar, además, una amplia red de sociedades mutuas de menor tamaño que estaban exentas de la obligación de inscribirse en el registro oficial, pero que también operaban en el sector ${ }^{22}$.

No obstante, el hecho de que el seguro de paro fuese predominantemente de base sindical no significa que los fondos sindicales estuviesen exentos de problemas. A partir del informe de González y Oyuelos (1914), citado anteriormente, se puede distinguir entre tres tipos de servicios que las asociaciones obreras ofrecían a sus afiliados: 1) exención de la cotización durante el desempleo, 2) servicio de colocación y/o registro de parados y 3) prestaciones en metálico, es decir, seguro de paro propiamente dicho. Según el informe, en 1914 había en España un total de 587 asociaciones obreras con 84.415 asegurados que ofrecían alguno de estos servicios; de las cuales, únicamente 117 asociaciones con 14.393 asegurados ofrecían prestaciones en metálico, lo que representaba un $0,19 \%$ de la población activa ${ }^{23}$ (Cuadro 1). Como se dijo antes, es posible que estas cifras estén sesgadas a la baja; de hecho, de las 49 provincias que se recogen en el estudio, tan solo 17 cuentan con algún asegurado. En el resto, el número de asegurados es cero o no existen datos, lo que sugiere que se trata de una estadística bastante incompleta.

22 En 1915, por ejemplo, había 1.065 sociedades mutuas acogidas a dicha excepción, muchas de ellas agrupadas en federaciones provinciales de ámbito superior. Véanse Pons (2002) y Pons y Vilar (2011)

${ }^{23}$ Las cifras de población activa son del año 1910 y provienen de Nicolau (2005). 
Entre las provincias para las que sí existen datos, las cifras oscilan entre los 29 asegurados de la provincia de Almería o los 40 de Badajoz, que representaban un 0,02\% de la población activa, y los 2.601 asegurados de Madrid o los 884 de Santander, que representaban, respectivamente, un $0,75 \%$ y un $0,79 \%$ de la población activa. La única provincia donde la cifra de asegurados superaba el 1\% era Toledo, donde el número de asegurados era particularmente alto comparado con el resto de provincias: 2.336 asegurados que representaban un $1,62 \%$ de la población activa ${ }^{24}$. Teniendo en cuenta que las cifras sobre Madrid deben ser de las que mejor se ajustan a la realidad (la capacidad del IRS y el INP para recabar información seguramente era superior que en la mayoría de provincias), y teniendo en cuenta que el caso de Toledo parece atípico y representaría un techo máximo; resulta razonable pensar que el número de asegurados para el conjunto de España se encontraba entre un 0,5 y un $1,5 \%$ de la población activa. No obstante, incluso con esta revisión al alza de las cifras de González y Oyuelos (1914), todo parece indicar que los fondos sindicales contra el paro tuvieron más dificultades para desarrollarse que las mutuas que cubrían otros riesgos sociales como la enfermedad.

En 1915, las mutuas con seguro de enfermedad contaban con 231.616 $\operatorname{asegurados}^{25}$, a los que habría que sumar los asegurados en compañías mercantiles; pero no existe información sobre ellos ${ }^{26}$. En cualquier caso, los 231.616 mutualistas asegurados representaban un 3,07\% de la población activa, una cifra no muy elevada si lo comparamos con los niveles actuales de protección social, pero bastante por encima de la cobertura privada contra el paro. De nuevo, es difícil determinar las causas de este fenómeno. Por un lado, los problemas de riesgo moral son particularmente intensos en el caso del desempleo. Como se dijo antes, esto pudo ser un obstáculo para la entrada de compañías privadas, reduciendo por tanto el potencial de crecimiento de la protección privada contra el paro. Otro obstáculo importante para el desarrollo de los fondos contra el paro era el hecho de que, en determinadas circunstancias, la probabilidad del riesgo de paro era muy elevada. En caso de depresión cíclica, por ejemplo, los índices de desempleo se disparan, las reservas se agotan con facilidad y el seguro es inviable bajo parámetros estrictamente actuariales. Posiblemente, esto lastró el funcionamiento de los fondos contra el paro en mayor medida que otros riesgos sociales ${ }^{27}$. Por último, hay que añadir

${ }^{24}$ Las cifras de población activa provincial provienen de Martínez Galarraga (2007), quien las calculó para elaborar su estimación del PIB provincial en España. Aunque en el documento de trabajo citado no fueron publicadas, el autor las ha proporcionado amablemente.

25 Datos de Pons y Vilar (2011), Tabla 2. Se han sumado las mutuas que ofrecían prestaciones en metálico y las que ofrecían asistencia médica y farmacéutica.

26 Pons y Vilar (2011).

27 En el caso del seguro de enfermedad, las epidemias implicaban un problema similar, pero las mutuas normalmente excluían la cobertura de las enfermedades por epidemia (Vilar, 2010). En el caso del paro, sin embargo, los fondos sindicales cubrían indistintamente el desempleo friccional y 
que el riesgo de enfermedad estaba presumiblemente menos concentrado que el de desempleo, lo que generaba más incentivos entre muchos trabajadores para asegurarse y un mercado potencial más amplio para las entidades aseguradoras.

\subsection{La protección privada contra el paro después de 1914}

Después de 1914, el INP no volvió a publicar ningún estudio similar al de González y Oyuelos (1914). Por tanto, hay que recurrir a fuentes alternativas para conocer la evolución de los fondos privados de paro. Una de ellas son los concursos organizados por la Sociedad Española para el Estudio del Problema del Paro, que era una organización privada, aunque muchos de sus miembros eran políticos destacados, miembros del INP y del IRS, o intelectuales de reconocido prestigio ${ }^{28}$. El objetivo de esta organización era «estudiar, en todos sus aspectos y modalidades, el problema del paro [y] aplicar en lo posible soluciones al mismo ${ }^{29}$. Entre sus trabajos destacan los concursos mencionados que tenían por objetivo incentivar la previsión privada contra el paro mediante la entrega de premios a las entidades (ya fuesen obreras, patronales o mixtas) que cubriesen el riesgo de desempleo. Los premios se concedían en función de aspectos como el número de parados que recibían la prestación, el importe de las mismas, la antigüedad de los socios, las cuotas exigidas y otros criterios similares.

Gracias al Boletín del IRS, se ha podido obtener información de las convocatorias referentes a los años 1914, 1916-1917 y 1917-1918. Así, en la convocatoria de 1914 se presentaron 17 asociaciones, aunque únicamente existe información sobre el número de asegurados para siete de ellas (que en total ascendía a 2.791 trabajadores). Sobre las 10 asociaciones restantes no aparece información. En la convocatoria de 1916-1917, se presentaron también 17 asociaciones, pero no existe información sobre el número de asegurados. Finalmente, en la convocatoria de 1917-1918, se presentaron otras 17 asociaciones (que no fueron las mismas que en ediciones anteriores), con un total de 12.336 asegurados (Cuadro 2). Esta cifra se encuentra tan solo ligeramente por debajo de los 14.393 asegurados que, según el informe de González y Oyuelos, había en España en 1914. Sin embargo, nuevamente es muy posible que las cifras que se desprenden de los concursos de la Sociedad Española para el Estudio del Problema del Paro estén sesgadas a la baja.

\footnotetext{
(F'note continued)

el desempleo cíclico, ya que, a diferencia de una enfermedad epidémica, no existían síntomas externos que permitiesen distinguirlos.

28 Por ejemplo, Eduardo Dato, Gumersindo de Azcárate y José Canalejas fueron presidentes de honor; el vizconde de Eza, presidente; José Maluquer, vicepresidente; y Adolfo Buylla, vocal de la Junta Directiva. La Sociedad Española para el Estudio del Problema del Paro era una asociación privada, independiente del INP y del IRS, pero colaboraron estrechamente en varias ocasiones. Véase González y Oyuelos (1914), y Sangro (1908).

29 Sangro (1911, p. 23).
} 


\section{CUADRO 2}

LA PROTECCIÓN PRIVADA CONTRA EL PARO SEGÚN LA SOCIEDAD ESPAÑOLA PARA EL ESTUDIO DEL PROBLEMA DEL PARO (1914-1918)

\begin{tabular}{|l|c|c|c|c|}
\hline & & & \multicolumn{2}{|c|}{ Asociaciones radicadas en Madrid } \\
\hline & Número de asociaciones & Asegurados & Número & Asegurados \\
\hline $\mathbf{1 9 1 4}$ & 17 & $2.791^{*}$ & 9 & - \\
$\mathbf{1 9 1 6 - 1 9 1 7}$ & 17 & - & 13 & - \\
$\mathbf{1 9 1 7 - 1 9 1 8}$ & 17 & 12.336 & 13 & 9.022 \\
\hline
\end{tabular}

Fuentes: Boletín del IRS, año XIII, núm. 140, febrero 1916; Boletín IRS, año XV, núm. 167, mayo 1918; Boletín IRS, núm. 180, junio 1919.

*La cifra de asegurados se refiere a 7 de las 17 asociaciones.

En primer lugar, estos datos únicamente hacen referencia a las asociaciones que, efectivamente, se presentaron a los concursos, aunque es posible que muchas entidades no se presentaran. De hecho, como se observa en el Cuadro 2, los datos muestran un sesgo geográfico considerable. La mayoría de las asociaciones estaban radicadas en Madrid (en 1914, nueve de las 17 asociaciones registradas; y entre 1916 y 1918, 13 de las 17 asociaciones registradas). Seguramente, esto se explica porque es allí donde se encontraba la sede de la Sociedad Española para el Estudio del Problema del Paro, lo que sugiere que la proximidad geográfica condicionó la participación en los concursos. Si nos centramos en el caso de Madrid, que parece más representativo que el cuadro ofrecido para el conjunto de España, se puede observar que en 1917-1918 el número de asegurados contra el paro era de 9.022 trabajadores; lo que representaba un $2,26 \%$ de la población activa ${ }^{30}$.

Esta cifra es significativamente más alta que la tasa de cobertura del $0,75 \%$ de la población activa que, según el informe de González y Oyuelos, había en Madrid en 1914. En ese sentido, es posible que el crecimiento en el número de asegurados se deba a los flujos migratorios del campo a la ciudad que hubo durante la primera guerra mundial. Entre 1910 y 1920, el porcentaje de población ocupada en la agricultura disminuyó de un 66\% a un $57,2 \%$ de la población activa total ${ }^{31}$. Y, como se verá en el próximo apartado, los fondos sindicales contra el paro se desarrollaron sobre todo entre trabajadores vinculados a actividades urbanas. Por otro lado, también

30 La población activa de Madrid se ha obtenido del censo de población de 1920, t. V. A la cifra de población total se han restado las siguientes categorías, que se han considerado inactivos: propietarios que viven principalmente del producto de la locación de sus inmuebles, rentistas, retirados o pensionados del Estado y de otras Administraciones públicas o privadas, alumnos de primera enseñanza, estudiantes, acogidos en hospicios y hospitales, locos y enajenados, presos, mendigos, vagabundos y prostitutas, individuos sin profesión, miembros de la familia, niños sin profesión por razón de su edad. La cifra de población activa resultante ha sido de 399.987 personas.

31 Nicolau (2005). 
es posible que estas diferencias se deban, simplemente, a que estamos comparando dos fuentes distintas. Los concursos de la Sociedad Española para el Estudio del Problema del Paro implicaban un premio económico y, por tanto, es posible que los sindicatos tuviesen más incentivos para presentarse que cuando se trataba de una encuesta realizada por el Gobierno (al menos ese podría haber sido el caso de las asociaciones radicadas en Madrid que debieron tener más facilidades que el resto para hacer los trámites).

Otra fuente de información alternativa son los informes sobre las subvenciones que el Gobierno concedió entre 1924 y 1931 a las entidades que cubrían el riesgo de desempleo al amparo del decreto de abril de 1923. Como se vio anteriormente, en 1922 el Gobierno incluyó en la ley de presupuestos una partida para crear un "fondo de paro" y subvencionar a dichas entidades. Las bases para gestionar estos recursos se sentaron en el real decreto de 27 de abril de 1923, de forma que el importe de las subvenciones se estableció en un 25\% de las prestaciones satisfechas por las mutuas y sindicatos; y para tener derecho a las subvenciones, las prestaciones de paro no podían superar el $60 \%$ del salario, ni tener una duración superior a 90 días al año. En 1925, este fondo de subvenciones quedó congelado, pero se reestableció gracias a la real orden de 31 de diciembre de 1927. En consecuencia, en 1929, 1930 y 1931 se volvieron a conceder subvenciones al amparo del decreto de abril de 1923. Finalmente, cuando entró en vigor el seguro público de desempleo aprobado por el Gobierno republicano en 1931, el fondo de subvenciones creado al amparo del decreto de 1923 perdió su vigencia.

El alcance de estas medidas fue, sin embargo, muy limitado. Las subvenciones concedidas por el Gobierno fueron muy reducidas, lo que, por otro lado, no resulta sorprendente teniendo en cuenta que estas dependían de las indemnizaciones previamente abonadas por los fondos sindicales y que la afiliación obrera apenas superaba el $10 \%$ de la población activa en $1919^{32}$. Como se puede ver en el Cuadro 3, en 1923 las subvenciones del Gobierno supusieron un total de 45.663 pesetas; mientras que en 1929, 1930 y 1931 supusieron $70.000,62.127$ y 70.000 pesetas, respectivamente. Para tener una referencia, en 1931 estas 70.000 ptas. representaron un 0,0018\% del gasto total del Estado, que ascendió a 3.853.000.000 pesetas ${ }^{33}$. A partir de los registros de las subvenciones concedidas no es posible saber el número de asegurados contra el paro, pero sí se puede conocer el número de asociaciones que se beneficiaron de dichas subvenciones y el importe de las prestaciones que abonaron. Nuevamente, es muy posible que estas cifras tengan un sesgo a la baja, ya que pudo haber asociaciones que no recibieron la subvención gubernamental, ya fuese por falta de información o por cualquier otro motivo. Sin embargo, este parece un indicador razonable de la evolución (aunque no del nivel) de la protección privada contra el paro entre 1924 y 1931.

\footnotetext{
32 Tasa calculada a partir de Silvestre (2003), apéndice 3, y Nicolau (2005).

33 Comín y Díaz (2005), Cuadro 12.18.
} 
CUADRO 3

SUBVENCIONES CONCEDIDAS Y ASOCIACIONES BENEFICIARIAS DEL REAL DECRETO DE 27 DE ABRIL DE 1923

\begin{tabular}{|l|c|c|c|c|c|}
\hline Año & $\begin{array}{c}\text { Número } \\
\text { de asocia- } \\
\text { ciones }\end{array}$ & $\begin{array}{c}\text { Subvenciones } \\
\text { (ptas. cor- } \\
\text { rientes) }\end{array}$ & $\begin{array}{c}\text { Subvenciones } \\
\text { (ptas. ctes. } \\
\text { de 1924) }\end{array}$ & $\begin{array}{c}\text { Prestaciones } \\
\text { (ptas. cor- } \\
\text { rientes) }\end{array}$ & $\begin{array}{c}\text { Prestaciones } \\
\text { (ptas. ctes. } \\
\text { de 1924) }\end{array}$ \\
\hline $\mathbf{1 9 2 4}$ & 11 & $45.663,05$ & $45.663,05$ & $182.250,25$ & $182.250,25$ \\
$\mathbf{1 9 2 9}$ & - & $70.000,00$ & $73.937,10$ & $696.864,00$ & $736.058,65$ \\
$\mathbf{1 9 3 0}$ & - & $62.127,00$ & $63.041,06$ & $767.869,00$ & $779.166,42$ \\
$\mathbf{1 9 3 1}$ & 27 & $70.000,00$ & $70.434,42$ & $899.438,73$ & $905.020,70$ \\
\hline
\end{tabular}

Fuentes: los datos de 1924 provienen de Posada (1924), los de 1929 y 1930 de Caja Nacional contra el Paro Forzoso (1934), y los de 1931 de la orden de 30 de diciembre de 1931.

Como muestra el cuadro 3, el número de asociaciones que practicaban el seguro de paro creció rápidamente; pero, incluso en 1931, solo 27 asociaciones en todo el país se beneficiaron de la subvención gubernamental. Si se analiza la evolución de las prestaciones satisfechas por estas entidades se observa algo similar. Entre 1924 y 1931 fueron creciendo de forma constante pero, en 1931, tan solo representaban un $0,002 \%$ del PIB, lo que refleja la escasa incidencia que las prestaciones (privadas) contra el paro alcanzaron en España antes de la guerra civil ${ }^{34}$. Si comparamos la situación con otros países europeos obtenemos algo similar. Según los datos que tenemos sobre España, en 1914 la tasa de la cobertura privada contra el paro estaba entre un 0,5 y un 1,5\% de la población activa, y en 1917-1918 debía estar próxima al $2 \%$ de la población activa (suponiendo que los niveles de cobertura que se derivan de los informes de la Sociedad Española para el Estudio del Problema del Paro sobre Madrid fuesen extrapolables al conjunto de España, lo que seguramente es una sobrevaloración). En Alemania, en cambio, en 1912 había 2.371.256 asegurados, que representaban un 8,44\% de la población activa $^{35}$; y en Gran Bretaña, en 1908 había 1.473 .593 asegurados, que representaban un $8,03 \%$ de la población activa ${ }^{36}$.

\section{4. ¿QUIÉNES ERAN LOS BENEFICIARIOS DEL SEGURO?}

¿Por qué el seguro de paro de base sindical tuvo una incidencia tan limitada en España? A menudo se considera que tanto las mutuas como los fondos sindicales fueron una respuesta de los trabajadores a las necesidades

\footnotetext{
34 PIB tomado de Prados de la Escosura (2003).

35 González y Oyuelos (1914, pp. 258-260). La población activa hace referencia al año 1907 y proviene de Flora (1983).

${ }^{36}$ Harris (2004, p. 85). La población activa es del año 1911 y proviene de Flora (1983).
} 
crecientes provocadas por la industrialización y la difusión del trabajo asalariado. En palabras de Cuesta (1987), las mutuas «constituyen una forma específica con la que el proletariado reacciona no directamente a las condiciones de explotación [en la fábrica], sino de miseria [...], organizándose ante los problemas de la existencia: especialmente la muerte, la enfermedad y el paro» (p. 302). En una línea similar, Di Mateo y Emery (2002) muestran en un estudio empírico que el crecimiento urbano estimuló la demanda del seguro de vida a finales del siglo XIX en Ontario (Canadá); lo que según los autores se explica, precisamente, por la mayor dependencia del salario que existe en las zonas urbanas.

No obstante, una de las principales limitaciones que se atribuye a las mutuas y los fondos sindicales es que a menudo solo protegían a los trabajadores de ingresos elevados. En su estudio sobre el desempleo en Gran Bretaña, Beveridge (1989 [1944]) explica que los trabajadores que se acogían a los programas oficiales de obras públicas no tenían ningún tipo de seguro contra el paro y que el objetivo del seguro creado en Gran Bretaña en 1911 era, de hecho, ampliar la cobertura más allá de los trabajadores cualificados organizados en sindicatos. De forma similar, Murray (2007) muestra que la demanda del seguro de enfermedad en los Estados Unidos en el siglo XIX estaba correlacionada con el nivel de ingresos (a mayores ingresos más probable era que los trabajadores contratasen un seguro). Asimismo, en la historiografía española también se ha señalado que los miembros de las mutuas pertenecían a menudo a la llamada "aristocracia obrera», en el sentido de que sus miembros acostumbraban a ser obreros cualificados o artesanos con cierta estabilidad en el empleo y capacidad de ahorro ${ }^{37}$. Como ha señalado Gorsky (1998), si se lleva al extremo, esta realidad parece entrar en contradicción con la tesis de la aparición de las mutuas como respuesta a las necesidades de los trabajadores, lo que plantea un interrogante: ifueron las mutuas una respuesta frente a necesidades crecientes?, ¿o, más bien, fueron el resultado del incremento de la capacidad de ahorro y consumo que trajo consigo el crecimiento económico, y por eso solo las contrataron los trabajadores de ingresos más altos?

Seguramente, se trató de ambas cosas a la vez, en el sentido de que la difusión del trabajo asalariado generó nuevas demandas que los trabajadores de mayores ingresos pudieron afrontar mejor. Aplicando este razonamiento al caso del desempleo, inicialmente sería de esperar 1) que el seguro de paro estuviese más extendido en las áreas urbanas y 2) que estuviese más difundido entre los trabajadores de renta alta. El informe de González y Oyuelos (1914), citado anteriormente, aporta información desagregada por provincias sobre el número de asegurados. Sin embargo, como muestra el Gráfico 1, no parece que haya relación entre la tasa de cobertura provincial (asegurados/población activa total) y la población activa urbana (expresada

\footnotetext{
${ }^{37}$ Cf. Castillo (1994) y Vilar (2010).
} 


\section{GRÁFICO 1}

COBERTURA CONTRA EL PARO FRENTE A POBLACIÓN ACTIVA URBANA (1914)

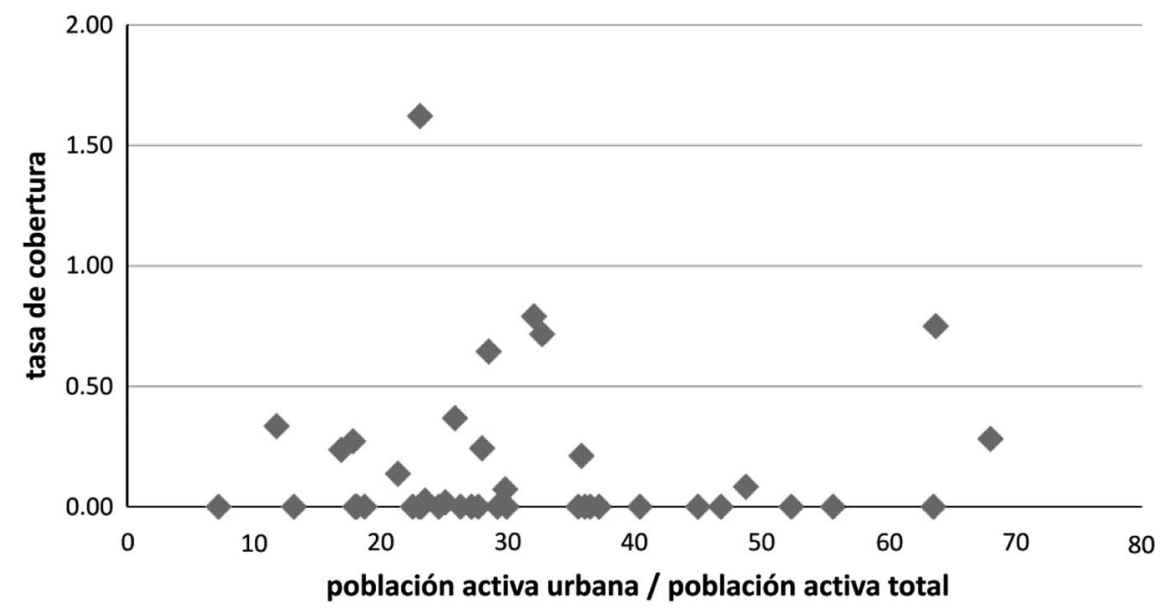

Fuentes: la cifra de asegurados proviene de González y Oyuelos (1914). Los datos de población activa son de 1910 y provienen de Martínez Galarraga (2007). La población activa urbana es la suma de la industria y los servicios.

en porcentaje sobre la población activa provincial). De forma similar, los Gráficos 2 a 4 sugieren que no hay relación entre la tasa de cobertura provincial y el nivel salarial de cada provincia (independientemente de si utilizamos el salario industrial cualificado, no cualificado o agrario). Sin embargo, sería precipitado concluir que la demanda individual del seguro de desempleo no está en absoluto relacionada con la urbanización y el nivel salarial. Como se vio en el apartado anterior, el seguro privado de paro en este periodo estaba muy poco desarrollado (de hecho, muchas provincias no tenían ni un solo asegurado), por lo que no es de extrañar que no se observen patrones claros.

También es posible que exista un problema de inferencia estadística debido a la utilización de datos provinciales. Tomemos, por ejemplo, el caso de Toledo, que en el Gráfico 1 es el punto que se observa con la tasa de cobertura más alta, pero con uno de los porcentajes de población activa urbana más bajos. Inicialmente, se podría pensar que no existe relación entre ambas variables; sin embargo, podría darse el caso de que (a pesar de que la población activa urbana representaba un bajo porcentaje sobre el total) todos o la mayoría de los trabajadores que tenían contratado un seguro de desempleo estuviesen ocupados en la industria o en los servicios. Lo mismo podría decirse de los salarios. Continuando con el ejemplo de Toledo, a pesar de que el nivel salarial en dicha provincia no era de los más altos, es 


\section{GRÁFICO 2 \\ COBERTURA CONTRA EL PARO FRENTE A SALARIOS INDUSTRIALES \\ CUALIFICADOS (1914)}

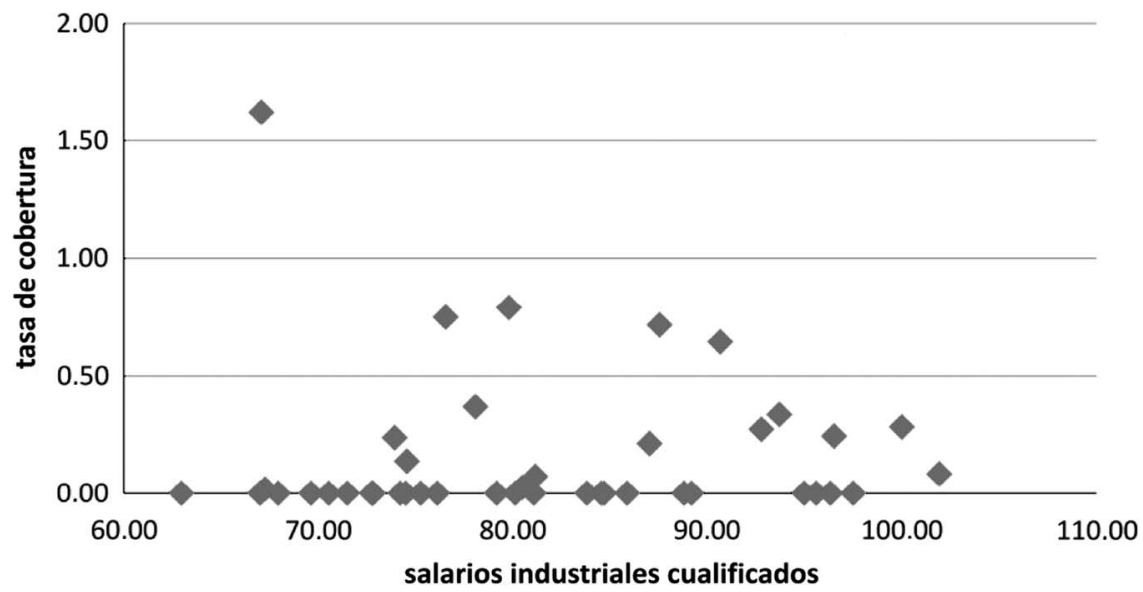

Fuentes: Los asegurados de González y Oyuelos (1914). Los datos salariales están expresados en base 100 tomando como referencia los valores de Barcelona en 1914 y provienen de Rosés y Sánchez-Alonso (2004).

\section{GRÁFICO 3}

COBERTURA CONTRA EL PARO FRENTE A SALARIOS INDUSTRIALES NO CUALIFICADOS (1914)

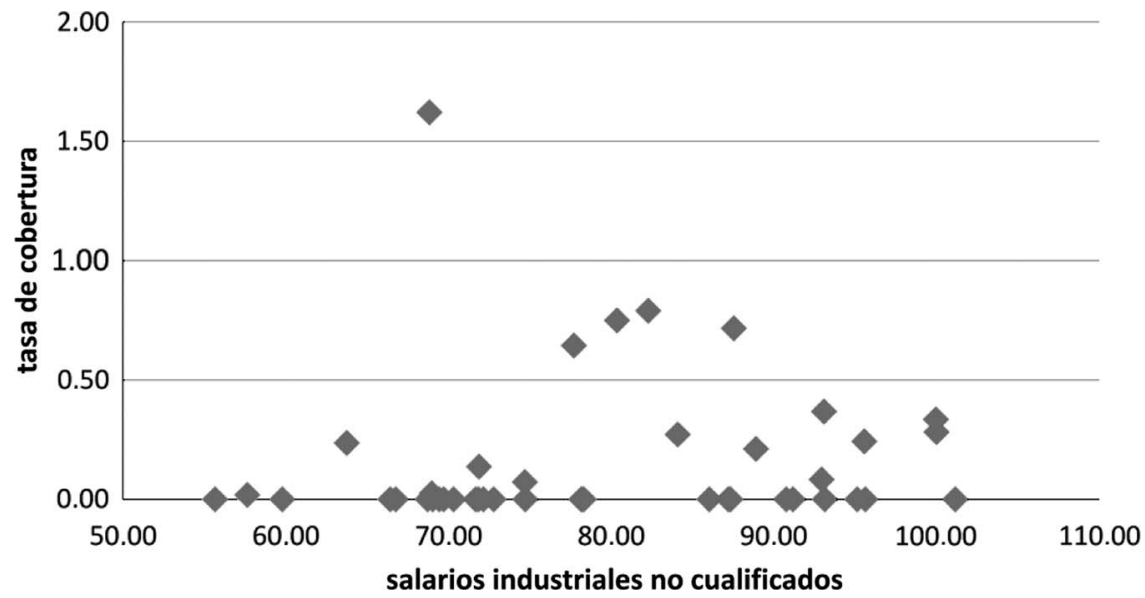

Fuentes: véase Gráfico 2. 
GRÁFICO 4

COBERTURA CONTRA EL PARO FRENTE A SALARIOS AGRARIOS (1914)

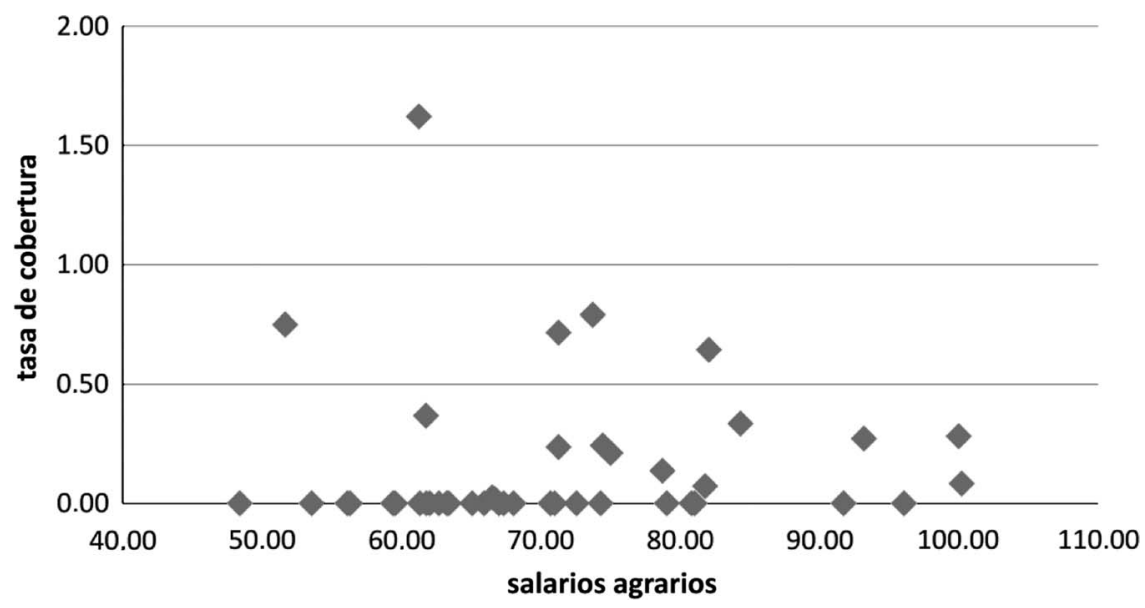

Fuentes: véase Gráfico 2.

posible que los trabajadores que efectivamente tenía contratado un seguro de desempleo tuviesen salarios altos, con independencia del salario provincial.

Lo ideal para analizar la relación entre la demanda individual del seguro y el nivel salarial y el proceso de urbanización sería tener información individualizada sobre el nivel salarial de los trabajadores asegurados y sobre si estos pertenecían a ocupaciones rurales o urbanas. El estudio de González y Oyuelos (1914) no ofrece información desagregada a ese nivel. Sin embargo, una forma alternativa de contrastar si el seguro de paro estaba más extendido en las áreas urbanas, consiste en identificar el sector $\mathbf{u}$ oficio al que pertenecían los asegurados. En el periodo que nos ocupa, muchas de las organizaciones obreras que ofrecían cobertura contra el paro eran sindicatos de oficios y sus nombres eran bastante descriptivos, como, por ejemplo: Asociación de Impresores o Sociedad de Obreros Marmolistas, y, por tanto, es relativamente fácil identificar el sector u oficio al que pertenecían. Para rastrear el nombre de las asociaciones que cubrían el riesgo de paro se han utilizado dos fuentes alternativas: los informes de los concursos de la Sociedad Española para el Estudio del Problema del Paro y los informes de las subvenciones que el Ministerio de Trabajo concedió al amparo del real decreto de abril de 1923.

El Cuadro 4 muestra dicha información. Como se puede ver, parece que todas las mutuas y sindicatos registrados tanto en los concursos de la Sociedad Española para el Estudio del Problema del Paro como los que recibieron subvenciones del Gobierno pertenecían a la industria o los 
CUADRO 4

MUTUAS Y SINDICATOS QUE CUBRÍAN EL RIESGO DE PARO SEGÚN LOS CONCURSOS DE LA SOCIEDAD ESPAÑOLA PARA EL ESTUDIO DEL PROBLEMA DEL PARO Y LAS SUBVENCIONES DEL MINISTERIO DE TRABAJO (1914-1931)

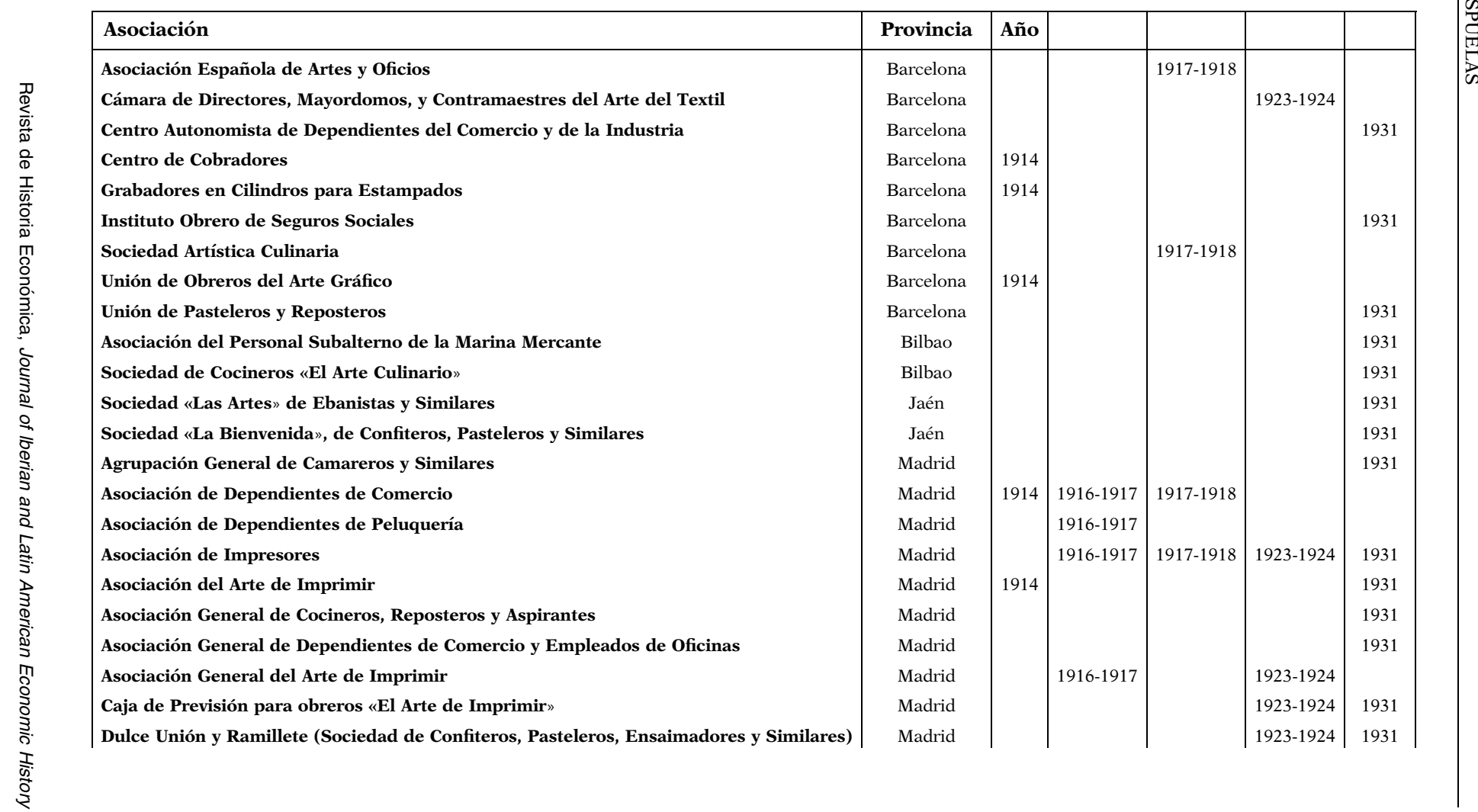


CUADRO 4 (Cont.)

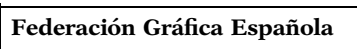

\begin{tabular}{c|} 
Madrid \\
Madrid \\
Madrid \\
Madrid \\
Madrid \\
Madrid \\
Madrid \\
Madrid \\
Madrid \\
Madrid \\
Madrid \\
Madrid \\
Madrid \\
Madrid \\
Madrid \\
Madrid \\
Madrid \\
Madrid \\
Madrid \\
Madrid \\
Madrid \\
Málaga \\
Murcia \\
Santander \\
Sevilla \\
Valencia
\end{tabular}

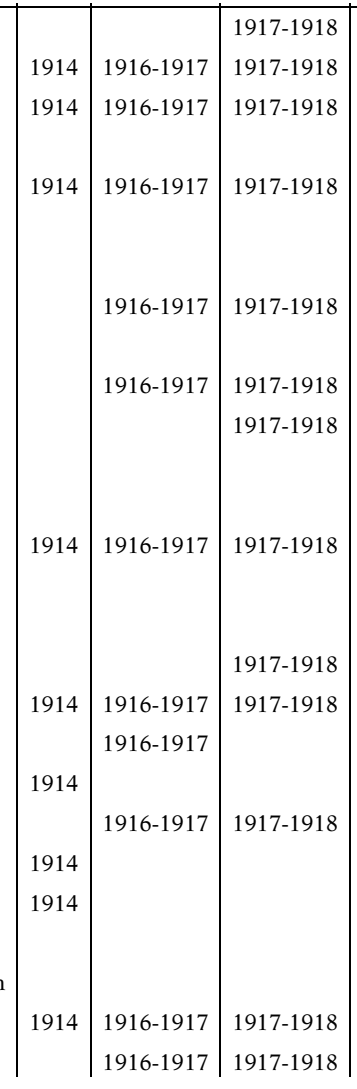


CUADRO 4 (Cont.)

\begin{tabular}{|c|c|c|c|c|}
\hline Asociación & Provincia & Año & & \\
\hline Asociación del Arte de Imprimir & Valladolid & 1914 & 1916-1917 & \\
\hline Sindicato Obrero Metalúrgico & Zaragoza & 1914 & 1916-1917 & \\
\hline Asociación General de Dependientes de la Administración y Distribución & n. d. & & & 1923-1924 \\
\hline Montepío de Dependientes del Gremio de Curtidos & n. d. & & & 1923-1924 \\
\hline
\end{tabular}

Fuentes: para los concursos de la Sociedad Española para el Estudio del Problema del Paro, cf. las mismas que en el Cuadro 2; para las subvenciones del Ministerio de Trabajo, cf. las mismas que en el Cuadro 3. 
servicios. En cambio, ninguna de estas asociaciones pertenecía al sector agrario. Es cierto que no es posible descartar que hubiese mutuas y sindicatos con seguro de paro en la agricultura (como se dijo antes, seguramente hubo asociaciones que no se presentaron a los concursos de la Sociedad Española para el Estudio del Problema del Paro ni solicitaron las subvenciones del Ministerio de Trabajo); sin embargo, todo parece indicar que, efectivamente, en el periodo anterior a la guerra civil, los trabajadores con seguro de desempleo pertenecían mayoritariamente a sectores que no estaban vinculados a actividades agrarias.

Por otro lado, ni los informes sobre los concursos de la Sociedad Española para el Estudio del Problema del Paro ni los informes sobre las subvenciones concedidas por el Ministerio de Trabajo aportan información sobre el nivel de ingresos de los trabajadores asegurados. Sin embargo, como la mayoría de asociaciones que cubrían el riesgo de paro pertenecían a profesiones específicas, es posible obtener información sobre el salario (medio) de cada profesión a partir de la Estadística de los Salarios y Jornadas de Trabajo del Ministerio de Trabajo. Esto constituye un indicador bastante preciso del salario de los trabajadores asegurados, al menos más preciso que el salario provincial utilizado anteriormente. Los resultados se muestran en el Cuadro 5, donde se pueden apreciar los salarios/hora (tanto de los trabajadores cualificados como de los peones) de las profesiones a las que pertenecían las mutuas y sindicatos que cubrían el riesgo de paro. Asimismo, en la parte final de la tabla se muestran el salario medio no ponderado y el salario mediano del conjunto de sectores industriales recogidos en la Estadística de los Salarios y Jornadas de Trabajo. Toda la información se refiere a la provincia de Madrid, porque es donde existe información sobre un mayor número de asociaciones. En algunas ocasiones, el nombre de las mutuas o los sindicatos no ha sido suficiente para encontrar la profesión equivalente en la Estadística de los Salarios y Jornadas de Trabajo y, por tanto, no se han incluido en el Cuadro 5.

Como se puede ver, en la mayoría de profesiones donde había asegurados contra el paro, el salario/hora, tanto de los trabajadores cualificados como de los no cualificados, se encontraba por encima del salario/hora medio y del salario/hora mediano. Existen algunas excepciones, como el caso de los pintores, cuyo salario/hora (tanto en el caso de los trabajadores cualificados como de los peones) estaba por debajo del salario/hora medio y mediano, y, sin embargo, había asegurados contra el paro. No obstante, la evidencia sugiere que, en general, el seguro de desempleo fue más habitual entre los sectores profesionales con ingresos elevados. Esto ayudaría, a su vez, a explicar por qué los niveles de protección en España se encontraban lejos de Gran Bretaña o Alemania, que tenían niveles de renta más altos y estaban más urbanizados. Como se vio anteriormente, en 1914 la tasa de la cobertura privada contra el paro en España debía estar entre un 0,5 y un 1,5\% de la población activa, mientras que en Alemania y el Gran Bretaña superaba el 8\%. 
CUADRO 5

SALARIOS/HORA DE LOS SECTORES PROFESIONALES CON ASOCIACIONES QUE CUBRÍAN EL RIESGO DE PARO, PROVINCIA DE MADRID (1914-1924)

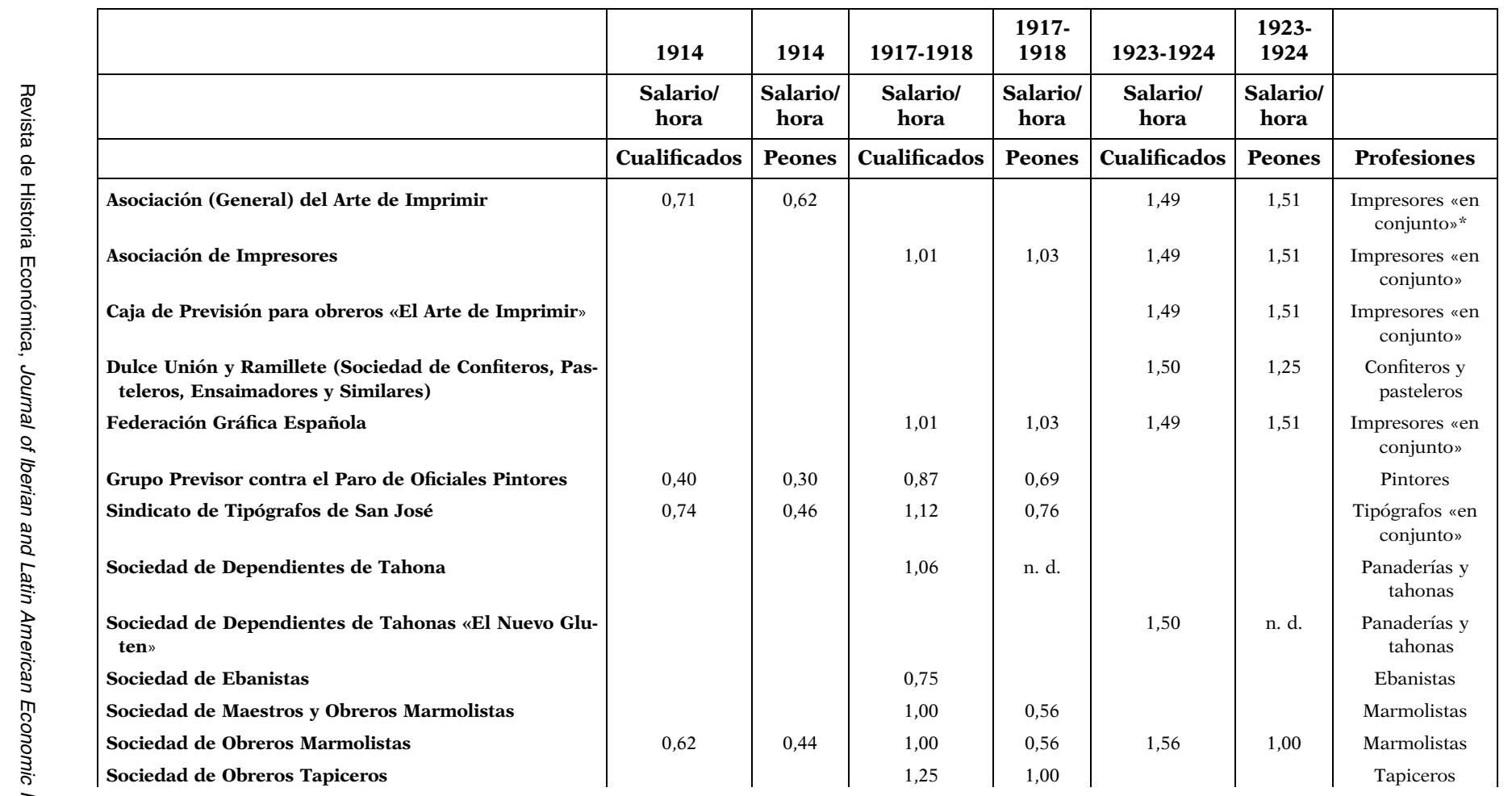


CUADRO 5 (Cont.)

\begin{tabular}{|c|c|c|c|c|c|c|c|}
\hline Sociedad de Plateros & 0,67 & 0,33 & 1,50 & 0,75 & & & Plateros \\
\hline Unión (General) de Auxiliares de Farmacia & 0,52 & n. d. & 1,14 & n. d. & 1,15 & n. d. & $\begin{array}{c}\text { Auxiliares de } \\
\text { farmacia }\end{array}$ \\
\hline Salario/hora medio (no ponderado) & 0,53 & 0,38 & 0,98 & 0,73 & 1,21 & 0,94 & \\
\hline Salario/hora mediano & $0,51-0,53$ & 0,36 & $0,93-0,95$ & $0,67-0,69$ & 1,20 & 0,89 & \\
\hline
\end{tabular}

Fuentes: para las asociaciones que cubrían el riesgo de paro véase el Cuadro 4; para los salarios/hora, Ministerio de Trabajo, Comercio a Industria (1927).

Notas: los periodos 1914, 1917-1918 y 1923-1924 se refieren a los años para los que tenemos información sobre las asociaciones que cubrían el riesgo de paro; sin embargo, la información sobre salarios/hora se refiere a los años 1914, 1920 y 1925, respectivamente.

"Es extraño que el salario cualificado de «impresores en conjunto» sea más bajo que el de los «impresores en conjunto» peones; posiblemente, esto se debe a que el salario cualificado de los «impresores en conjunto» es una media del salario cualificado de maquinistas, marcadores y litógrafos. Sin embargo, la Estadística de Salarios no aporta información sobre el salario no cualificado de maquinistas, marcadores y litógrafos y, por tanto, no se ha podido contrastar esta posibilidad ni hacer la corrección necesaria. 
No obstante, sería precipitado concluir que el desarrollo económico conllevaba, automáticamente, una mayor difusión del seguro de desempleo. En Francia, por ejemplo, los fondos sindicales contra el paro tan solo cubrían a un $0,16 \%$ de la población activa en 1902 y a un $0,25 \%$ en 1913 (y eso a pesar de que el Gobierno francés los había estado subvencionando desde 1905$)^{38}$. Una posible explicación de este fenómeno tiene que ver con las bajas tasas de afiliación francesas. En Gran Bretaña, la tasa de afiliación sindical en 1914 era de un 22,59\% de la población activa, y en Alemania de un 11,38\%. En Francia, en cambio, era de un 1,93\% de la población activa, una tasa muy baja para su nivel de desarrollo socioeconómico ${ }^{39}$. Desde este punto de vista, y teniendo en cuenta que los sindicatos eran quienes mayoritariamente ofrecían el seguro de desempleo, no resulta del todo sorprendente que los niveles de cobertura contra el paro fuesen tan bajos en ese país. A esto habría que sumar, además, que los sindicatos franceses tenían un marcado carácter contestatario, lo que según Martinet (1991, p. 133) se debía a que su afiliación estaba mayoritariamente compuesta por profesionales cualificados provenientes de empresas pequeñas y medianas, que se veían a sí mismos «en condiciones de prescindir del patrón» y mostraban inclinaciones revolucionarias. Lo cierto es que, a diferencia de otras centrales sindicales europeas, «la CGT [francesa] gastó pocas energías en la protección social de sus miembros, mientras que prefería poner el acento en su compromiso con el sindicalismo revolucionario» ${ }^{40}$.

En el caso español, los sindicatos vinculados a la UGT se mostraron ya a finales del siglo XIX favorables a la creación de fondos sindicales contra el paro (un ejemplo es la Sociedad Tipográfica de Socorros a Parados, fundada entre otros por Pablo Iglesias en 1883) y a la difusión de la «base múltiple», en general. De hecho, los seguros sociales de base sindical ayudaron a la UGT de Madrid a ampliar y consolidar su militancia durante las primeras décadas del siglo XX, hasta convertirse en un sindicalismo eminentemente de gestión en los años treinta ${ }^{41}$. Sin embargo, la afiliación a la UGT fue relativamente baja antes de la Segunda República (un 0,54\% de la población activa en 1910, un $2,70 \%$ en 1920 y un $3,19 \%$ en 1930), lo que seguramente limitaba la expansión del seguro ${ }^{42}$. La CNT, por su parte, sí que experimentó un fuerte crecimiento en el número de afiliados, pasando de un $0,38 \%$ de la población activa en 1911 a un $8,94 \%$ en $1919^{43}$, pero el sindicato fue ilegalizado y

${ }^{38}$ Los datos de asegurados de 1902 provienen de González y Oyuelos (1914, p. 259), la población activa es de 1906 y proviene de Flora (1983). Los asegurados y la población activa de 1913, de Flora (1983).

39 Crouch (1993).

40 Dutton (2002, p. 45)

41 González Gómez (1994).

42 Los datos de afiliación han sido tomados de Linz et al. (2005); los datos de población activa, de Nicolau (2005).

${ }^{43}$ Cifras de afiliación, de Silvestre (2003); población activa, de Nicolau (2005). 
reprimido durante la dictadura de Primo de Rivera, convirtiendo todas sus actividades en clandestinas. Además, todo parece indicar que la CNT, que apostaba por el sindicalismo revolucionario, no hizo muchos esfuerzos por difundir la «base múltiple» entre sus filas. De hecho, ya en 1932, Largo Caballero temía que el éxito del sistema de seguro de desempleo, que había introducido recientemente el Gobierno republicano, podría verse comprometido precisamente porque una parte importante del movimiento obrero prefería "apelar a la acción directa para sus reivindicaciones" en lugar de promover la base múltiple ${ }^{44}$.

Parece, por tanto, que los bajos niveles de renta y urbanización, característicos de la economía española, podrían ayudar a explicar por qué el seguro de paro de base sindical tuvo un alcance tan limitado en España, pero las bajas tasas de afiliación sindical e incluso la orientación ideológica de los sindicatos también debieron jugar un papel importante en ese sentido.

\section{EL FUNCIONAMIENTO DEL SEGURO PRIVADO CONTRA EL PARO}

A menudo, en la historiografía española, se ha considerado que «la aplicación de gestión moderna era francamente escasa, por no decir inexistente» ${ }^{45}$ en la mayoría de mutuas de finales del siglo XIX y principios del XX. Asimismo, Cuesta (1988, p. 173) considera que en «las primeras Cajas contra el Paro [...] la base técnica actuarial [no] estaba aún presente». Efectivamente, las técnicas de gestión debían ser arcaicas, especialmente si las comparamos con las que ahora utilizan la mayor parte de compañías comerciales. Sin embargo, lo que también es interesante desde el punto de vista histórico es saber si el funcionamiento de las entidades españolas era muy diferente al de las entidades de otros países europeos. Con ese objetivo, en este apartado se analiza el funcionamiento de los fondos sindicales contra el paro, prestando especial atención a la generosidad de las prestaciones y a las primas que pagaban los asegurados. Los informes de la Sociedad Española para el Estudio del Problema del Paro aportan de nuevo información muy valiosa en ese sentido. Estos recogen el importe de las prestaciones por desempleo y las cuotas que pagaban los asegurados. El único inconveniente es que, normalmente, aportan una cifra única, pero no especifican (y, por tanto, no se ha podido saber) si ello se debe a que las prestaciones eran fijas (iguales para todos los trabajadores) o si, por el contrario, reflejan prestaciones medias ${ }^{46}$.

A partir de estas cifras de prestaciones, se han calculado tasas de reemplazo para los años en que había cifras disponibles, que son 1914 y 1917-1918

44 Cf. Espuelas (2010, p. 210).

45 Castillo (1994, p. 25).

46 En otras ocasiones, aportan un intervalo, indicando, por ejemplo, que las prestaciones oscilaban entre 1 y 2 pesetas, pero no se especifica qué prestación correspondía para cada salario o cotización. 
(véase el Cuadro 6). La información sobre salarios (medios) por profesiones se ha tomado de la Estadística de Salarios ${ }^{47}$. El principal inconveniente a la hora de calcular las tasas de reemplazo es que, si bien en 1914 se han podido utilizar cifras de prestaciones y salarios de ese mismo año, en 1917-18 se han tenido que utilizar los salarios de 1920 (que son los que están disponibles en la Estadística de Salarios). Esto puede dar lugar a distorsiones notables, ya que la inflación entre 1917 y 1920 fue muy elevada. Por tanto, las tasas de reemplazo de 1917-1918 deben analizarse con precaución. Por otro lado, la Estadística de Salarios permite distinguir entre los salarios de los trabajadores cualificados y de los peones; de forma que se han podido calcular dos tasas de reemplazo: una «pesimista» (más baja), a partir de los salarios de los trabajadores cualificados, y otra «optimista» (más alta) a partir de los salarios de los peones.

Como se ve en el Cuadro 6, en 1914 las tasas de reemplazo muestran una variabilidad considerable según la profesión, oscilando entre un mínimo de un $21,13 \%$ y un máximo de un $50 \%$ del salario, si tomamos la tasa de reemplazo "pesimista», y entre un $24,19 \%$ y un $65,22 \%$ del salario, si tomamos la «optimista». En 1917-1918 también se observa bastante variabilidad, pero con niveles inferiores; así, la tasa de reemplazo osciló entre un $15 \%$ y un $35,38 \%$ del salario, si tomamos la estimación "pesimista», y entre un $15,17 \%$ y un $49,34 \%$, si tomamos la "optimista». Conviene remarcar que la caída en las tasas de reemplazo que se observa entre 1914 y 1917-1918 es posible que no sea real, y que simplemente se deba a que, como se apuntaba antes, para calcular las tasas de reemplazo de 1917-1918 se han utilizado los salarios nominales de 1920. En cualquier caso, las cifras del Cuadro 6 sugieren que en el caso de algunas organizaciones (como el Grupo Previsor contra el Paro de Oficiales Pintores o el Sindicato de Tipógrafos San José en 1914) las tasas de reemplazo podían alcanzar el 50 o el $60 \%$ del salario, lo que supone unos niveles no muy alejados de los actuales; pero, en la mayoría de profesiones, las tasas de reemplazo eran más bajas que en la actualidad, situándose en un $20-30 \%$ del salario.

Por otro lado, la duración máxima de las prestaciones también era muy corta. En 1914 oscilaban entre 30 y 90 días al año, dependiendo de la asociación (Cuadro 6), lo que supone en todos los casos una duración máxima muy inferior a las prestaciones actuales. Las prestaciones de los sindicatos españoles, sin embargo, no parecen muy diferentes de las que ofrecían otros sindicatos europeos. En Holanda, por ejemplo, la tasa de reemplazo durante las décadas de 1910 y 1920 oscilaba entre un $43 \%$ y un $65 \%$ del salario (dependiendo del año y de si se trataba de sindicatos socialistas o protestantes).

47 Idealmente, para calcular las tasas de reemplazo sería necesaria información individualizada sobre la prestación y el salario previo de cada trabajador. Sin embargo, para el periodo que nos ocupa, es imposible. Por tanto, las tasas de reemplazo construidas a partir de los salarios (medios) y las cifras de prestaciones de la Sociedad Española para el Estudio del Problema del Paro parecen una aproximación razonable. 
CUADRO 6

TASAS DE REEMPLAZO Y DURACIÓN MÁXIMA DE LAS PRESTACIONES CONTRA EL PARO, PROVINCIA DE MADRID (1914-1918)

\begin{tabular}{|c|c|c|c|c|c|c|c|c|c|}
\hline & Prestaciones & Salario/día* & $\begin{array}{l}\text { Salario/ } \\
\text { día* }\end{array}$ & $\begin{array}{c}\text { Tasa } \\
\text { reemp. }\end{array}$ & $\begin{array}{c}\text { Tasa } \\
\text { reemp. }\end{array}$ & Duración & Cuota & Prima & Prima \\
\hline & $\begin{array}{c}\text { por día } \\
\text { (pesetas) }\end{array}$ & Cualificados & Peones & "pesimista» & «optimista» & $\begin{array}{l}\text { máx. } \\
\text { (días) }\end{array}$ & $\begin{array}{r}\text { Semanal } \\
\text { (pesetas) }\end{array}$ & $\begin{array}{l}\text { (\% salario } \\
\text { cualificado) }\end{array}$ & $\begin{array}{l}\text { (\% sal- } \\
\text { ario } \\
\text { peones) }\end{array}$ \\
\hline & 1914 & 1914 & 1914 & 1914 & 1914 & 1914 & 1914 & 1914 & 1914 \\
\hline $\begin{array}{l}\text { Asociación (General) del } \\
\text { Arte de Imprimir }\end{array}$ & 1,5 & 7,10 & 6,20 & 21,13 & 24,19 & 90 & 0,25 & $0,59 \%$ & $0,67 \%$ \\
\hline $\begin{array}{l}\text { Grupo Previsor contra el } \\
\text { Paro de Oficiales Pin- } \\
\text { tores }\end{array}$ & 2 & 4,00 & 3,00 & 50,00 & 66,67 & 30 & 0,50 & $2,08 \%$ & $2,78 \%$ \\
\hline $\begin{array}{l}\text { Sindicato de Tipógrafos } \\
\text { de San José }\end{array}$ & 3 & 7,40 & 4,60 & 40,54 & 65,22 & 60 & 0,25 & $0,56 \%$ & $0,91 \%$ \\
\hline $\begin{array}{l}\text { Sociedad de Obreros } \\
\text { Marmolistas }\end{array}$ & 1,5 & 6,20 & 4,40 & 24,19 & 34,09 & 90 & n. d. & n. d. & n. d. \\
\hline Sociedad de Plateros & 2 & 6,70 & 3,30 & 29,85 & 60,61 & 30 & 0,50 & $1,24 \%$ & $2,53 \%$ \\
\hline \multirow{2}{*}{$\begin{array}{l}\text { Unión (General) de Aux- } \\
\text { iliares de Farmacia }\end{array}$} & 2 & 5,20 & n. d. & 38,46 & n. d. & 30 & 0,50 & $1,60 \%$ & n. d. \\
\hline & 1917-1918 & 1920 & 1920 & 1917-1918 & 1917-1918 & & 1917-1918 & & \\
\hline Asociación de Impresores & 1,5 & 8,08 & 8,24 & 18,56 & 18,20 & n. d. & 0,30 & & \\
\hline $\begin{array}{l}\text { Federación Gráfica Espa- } \\
\text { ñola }\end{array}$ & $1,25^{* *}$ & 8,08 & 8,24 & 15,47 & 15,17 & n. d. & $0,25^{* *}$ & & \\
\hline $\begin{array}{l}\text { Grupo Previsor contra el } \\
\text { Paro de Oficiales Pintores }\end{array}$ & 2 & 6,96 & 5,52 & 28,74 & 36,23 & n. d. & 0,50 & & \\
\hline
\end{tabular}


CUADRO 6 (Cont.)

\begin{tabular}{|c|c|c|c|c|c|c|c|c|c|}
\hline & Prestaciones & Salario/día* & $\begin{array}{c}\text { Salario/ } \\
\text { día* }\end{array}$ & $\begin{array}{l}\text { Tasa } \\
\text { reemp. }\end{array}$ & $\begin{array}{l}\text { Tasa } \\
\text { reemp. }\end{array}$ & Duración & Cuota & Prima & Prima \\
\hline & $\begin{array}{c}\text { por día } \\
\text { (pesetas) }\end{array}$ & Cualificados & Peones & «pesimista» & «optimista» & $\begin{array}{l}\text { máx. } \\
\text { (días) }\end{array}$ & $\begin{array}{l}\text { Semanal } \\
\text { (pesetas) }\end{array}$ & $\begin{array}{l}\text { (\% salario } \\
\text { cualificado) }\end{array}$ & $\begin{array}{c}(\% \text { sal- } \\
\text { ario } \\
\text { peones })\end{array}$ \\
\hline $\begin{array}{l}\text { Sindicato de Tipógrafos } \\
\text { de San José }\end{array}$ & 3 & 8,96 & 6,08 & 33,48 & 49,34 & n. d. & 0,25 & & \\
\hline $\begin{array}{l}\text { Sociedad de Depen- } \\
\text { dientes de Tahona }\end{array}$ & 3 & 8,48 & n. d. & 35,38 & n. d. & n. d. & 0,50 & & \\
\hline Sociedad de Ebanistas & 2 & 6 & n. d. & 33,33 & n. d. & n. d. & 0,60 & & \\
\hline $\begin{array}{l}\text { Sociedad de Maestros y } \\
\text { Obreros Marmolistas }\end{array}$ & $1,25 * *$ & 8 & 4,48 & 15,63 & 27,90 & n. d. & 0,75 & & \\
\hline $\begin{array}{c}\text { Sociedad de Obreros } \\
\text { Marmolistas }\end{array}$ & 1,5 & 8 & 4,48 & 18,75 & 33,48 & n. d. & 0,25 & & \\
\hline $\begin{array}{c}\text { Sociedad de Obreros } \\
\text { Tapiceros }\end{array}$ & $1,5^{* * *}$ & 10 & 8 & 15,00 & 18,75 & n. d. & 0,35 & & \\
\hline Sociedad de Plateros & 2 & 12 & 6 & 16,67 & 33,33 & n. d. & 0,50 & & \\
\hline $\begin{array}{l}\text { Unión (General) de Aux- } \\
\text { iliares de Farmacia }\end{array}$ & 3 & 9,12 & n. d. & 32,89 & n. d. & n. d. & 0,50 & & \\
\hline
\end{tabular}

Fuentes: las mismas que en el Cuadro 5.

*El salario/día se ha calculado a partir del salario/hora del Cuadro 5. En 1914, se ha supuesto que la jornada laboral era de 10 horas diarias, mientras que en 1920 se ha supuesto que eran 8 horas diarias.

**En lugar de indicar un valor único, en el informe de la Sociedad Española para el Estudio del Problema del Paro se indicaba una horquilla en la que la prestación o la cuota podían variar. En estos casos, se ha recogido el valor medio. En el caso de la Federación Gráfica Española, se indicaba la prestación semanal, y aquí se ha dividido entre 6 días laborables. 
La duración máxima también era similar, oscilando entre los 60 y los 90 días al año ${ }^{48}$. Como se vio en el apartado 2 , uno de los mecanismos que pueden utilizar los aseguradores para combatir los problemas de riesgo moral consiste en no cubrir completamente los costes que implican el riesgo que se está protegiendo (en el caso del desempleo, fijando prestaciones por debajo del salario habitual y con una duración limitada en el tiempo); y eso es precisamente lo que hicieron tanto los sindicatos españoles como los holandeses.

Desafortunadamente, no existen datos sobre la duración media del desempleo durante el periodo que nos ocupa; y, por tanto, es difícil precisar si estas prestaciones eran suficientes para cubrir las necesidades de los trabajadores. Según las estadísticas de la bolsa de trabajo de Barcelona, entre 1927 y 1929 el desempleo en esa provincia osciló entre un 2 y un 3\% de la población activa $^{49}$. Esto sugiere que se trataba de desempleo friccional y, presumiblemente, de corta duración, pero no podemos saber si estaba por encima de los 30-90 días máximos que fijaban las prestaciones. En cualquier caso, con unas prestaciones tan cortas difícilmente podía garantizarse la protección en los casos de crisis cíclicas (que, presumiblemente, harían aumentar el paro de larga duración) y se marginaba a los trabajadores con más probabilidades de caer y permanecer en el paro. A cambio, los fondos sindicales pudieron mantener primas que no parecen excesivas. En 1914, estas rondaban entre el 0,56\% y el 2,78\% del salario (Cuadro 6), mientras que en la actualidad representan el 1,6\% del salario. La alternativa habría sido prestaciones más generosas y, sobre todo, más largas; pero esto habría encarecido los costes y la prima del seguro. De hecho, como se vio en el apartado teórico, la única forma de hacer viable el seguro de paro para los trabajadores con muchas probabilidades de permanecer desempleados y en los casos de depresión cíclica es mediante subvenciones públicas que compensen el incremento de los costes.

Los sindicatos también intentaron controlar los problemas de selección adversa fijando largos periodos de carencia (que era una forma de disuadir a los «malos riesgos»). En la Federación Tipográfica de Madrid, por ejemplo, para tener derecho a la prestación era necesario estar afiliado durante 4 años seguidos ${ }^{50}$, lo que supone un periodo de carencia o de cotización previa mucho más largo que en la actualidad, que son 360 días. Además, el propio carácter sectorial de los sindicatos favorecía una cierta selección «automática». Como los trabajadores no cualificados seguramente tenían más probabilidades de perder su empleo que los trabajadores cualificados, también cambiaban más a menudo de sector u oficio, y por tanto tenían más dificultades para asegurarse, ya que, por definición, el seguro estaba limitado a un mismo sector u oficio. Esta selección «automática» entre «buenos» $\mathrm{y}$ «malos» riesgos (unido a los

\footnotetext{
48 Van Leeuwen (1997, Tablas 2 y 3).

49 Soto (1989, p. 344).

50 González Gómez (1994).
} 
largos periodos de carencia) también contribuía a que el seguro se difundiese más rápidamente entre los trabajadores con salarios elevados y mayor capacidad de ahorro, que presumiblemente eran los trabajadores cualificados que «pertenecían» a un oficio. Además, este carácter sectorial de los sindicatos también intensificaba su vulnerabilidad frente a posibles shocks de demanda, especialmente si se producían a escala sectorial. Nuevamente, como se vio en el apartado teórico, la forma más efectiva de solucionar los problemas de selección adversa, asegurando que todos los demandantes tienen acceso al seguro, es imponiendo el seguro obligatorio.

Curiosamente, las únicas medidas que podían adoptar los sindicatos para combatir los problemas de riesgo moral y selección adversa (prestaciones poco generosas y de corta duración, largos periodos de carencia, etc.), aunque ayudaban a mejorar la viabilidad de los fondos contra el paro, también limitaban el potencial de expansión del seguro (tanto en términos de afiliados como en las situaciones de paro que podían ser aseguradas). Por eso, incluso en Alemania y Gran Bretaña, donde el seguro de base sindical estaba muy desarrollado, las tasas de cobertura no superaban el 10\% de la población activa. En los pocos países donde, como en Suecia, el seguro de paro continuó estando gestionado por los sindicatos (bajo un sistema similar a lo que era el sistema de Gante), ello solo fue posible gracias a grandes subvenciones públicas, una fuerte regulación gubernamental y un sistema público complementario que ofrecía prestaciones no contributivas; lo que de hecho convertía al sistema sueco en un sistema público parcialmente gestionado por los sindicatos ${ }^{51}$.

\section{CONCLUSIONES}

En la España de antes de 1936, la protección privada contra el paro tuvo un alcance muy limitado. Los niveles de cobertura fueron inferiores a los de otros riesgos sociales, como la enfermedad, y el seguro estuvo fundamentalmente gestionado por fondos sindicales. Los problemas de riesgo moral (que en el caso del desempleo son mayores que en la mayoría de riesgos sociales) explican, en parte, la ausencia de las compañías comerciales en este ramo del seguro, ya que, a diferencia de los sindicatos, apenas tenían información sobre los asegurados. Por otro lado, los fondos contra el paro puede que tuvieran más dificultades que otros seguros sociales debido a su elevada vulnerabilidad frente a las crisis cíclicas y estacionales. El análisis detallado del caso español muestra, asimismo, que el seguro privado de paro se desarrolló con más facilidad entre los trabajadores vinculados a actividades urbanas con salarios elevados, lo que ayudaría a explicar por qué los niveles de protección se mantuvieron lejos de los de Gran Bretaña o

\footnotetext{
${ }^{51}$ Barr (1992).
} 
Alemania, que tenían niveles de renta más altos y estaban más urbanizados. No obstante, sería precipitado concluir que el desarrollo económico conlleva, automáticamente, una mayor difusión del seguro. Dado que este solía tener una base sindical, existen otros factores como las tasas de afiliación sindical e incluso la orientación ideológica de los sindicatos que son igualmente importantes para explicar las diferencias en los niveles de cobertura.

A las bajas tasas de cobertura del caso español hay que añadir, además, que las prestaciones contra el paro fueron muy poco generosas. Las tasas de reemplazo eran más bajas que en la actualidad y, sobre todo, tenían una duración máxima muy corta; y los periodos de cotización mínima exigida también eran más largos que en la actualidad. El objetivo de estas medidas no era otro que combatir los problemas de riesgo moral y selección adversa, pero también excluían en parte a los trabajadores no cualificados y no garantizaban la protección en casos de crisis cíclicas, por lo que limitaron el potencial de expansión del seguro. De hecho, como predice la teoría de los fallos de mercado, el seguro de paro es difícilmente viable sin la ayuda del Estado, lo que no significa que esta apareciese de forma automática allí donde existían problemas de eficiencia. En el caso español, por ejemplo, el seguro estatal se introdujo más tarde que en muchos países europeos. Es posible que factores como la tardía industrialización española, los persistentes problemas presupuestarios del Gobierno, la oposición empresarial a los proyectos de reforma social o incluso la falta de continuidad democrática ayuden a explicar las causas de este retraso, pero eso es algo que está fuera de los límites de este trabajo.

\section{BIBLIOGRAFÍA}

Alber, J. (1981): «Government responses to the Challenge of unemployment: the development of unemployment insurance in Western Europe», en P. Flora y A. J. Heidenheimer (eds.), The development of the Welfare States in Europe and America. New Brunswick y Londres: Transaction Books.

Bengoechea, S. y Borderías, C. (2010): «Paro, políticas laborales y género en la Cataluña republicana (1931-1936)», en M. J. Espuny y O. Paz Torres (coords.), Crisis y ocupación. Barcelona: Bosch.

Beveridge, W. H. (1989 [1944]) Pleno empleo en una sociedad libre. Madrid: Ministerio de Trabajo y Seguridad Social.

Caja nacional contra el paro forzoso: memoria correspondiente al año 1934. Madrid: Publicaciones del INP.

CARMONA, J. y Simpson, J. (2003): El laberinto de la agricultura española. Instituciones, contratos y organización entre 1850 y 1936. Zaragoza: Prensas Universitarias de Zaragoza.

Castillo, S. (1994): "Las Sociedades de Socorros Mutuos en la España Contemporánea», en S. Castillo (ed.), Solidaridad desde abajo: trabajadores 
y Socorros Mutuos en la España Contemporánea. Madrid: Centro de Estudios Históricos UGT.

Comín, F. y Díaz, D. (2005): "Sector público administrativo y Estado del Bienestar», en A. Carreras y X. Tafunell (coords.), Estadísticas históricas de España. Bilbao: Fundación BBVA.

Cuesta, J. (1987): «Las sociedades de socorros mutuos en la España de los años veinte. Un silencio en el reformismo social", en AA. VV., El Reformismo Social en España: la Comisión de Reformas Sociales. Actas de los IV Coloquios de Historia. Córdoba: Monte de Piedad y Caja de Ahorros de Córdoba.

Cuesta, J. (1988): Hacia los seguros sociales obligatorios. La crisis de la Restauración. Madrid: Ministerio de Trabajo y Seguridad Social.

Domenech, J. (2008): "Labour market adjustment a hundred years ago: the case of the Catalan textile industry, 1880-1913». Economic History Review 61 (1), pp. 1-25.

Espuelas, S. (2010): «El seguro de desempleo en España en la II República, 1931-1936. La evolución de las tasas de cobertura», en J. Pons y J. Silvestre (eds.), Los orígenes del Estado del Bienestar en España, 1900-1945: los seguros de accidentes, vejez, desempleo y enfermedad. Zaragoza: Prensas Universitarias de Zaragoza.

Espuny, M. J. (2010): «Ocupación, paro y género en las Bases de Trabajo de la Segunda República española», en M. J. Espuny y O. Paz Torres (coords.), Crisis y ocupación. Barcelona: Bosch.

Flora, P. (1983): State, economy and society in Western Europe, 1815-1975. Frankfurt: Campus.

FraX, E. y Matilla, M. J. (1996): «Los seguros en España: 1930-1934». Revista de Historia Económica XIV (1), pp. 183-203.

García GonzÁlez, G. (2010): «Los orígenes de la protección por desempleo en España: el seguro libre subsidiado de paro forzoso», en M. J. Espuny y O. Paz Torres (coords.), Crisis y ocupación. Barcelona: Bosch.

GonzÁlez Gómez, S. (1994): "La cotización sindical a "base múltiple", puerta de integración del mutualismo obrero en el primer sindicalismo socialista madrileño", en S. Castillo (ed.), Solidaridad desde abajo: trabajadores y Socorros Mutuos en la España Contemporánea. Madrid: Centro de Estudios Históricos y UGT.

González Rojas, F. y Oyuelos, R. (1914): Bolsas de Trabajo y Seguro contra el Paro Forzoso. Madrid: Publicaciones IRS.

Gorsky, M. (1998): «The Growth and Distribution of English Friendly Societies in the Early Nineteenth Century». The Economic History Review 51 (3), pp. 489-511.

HARris, B. (2004): The origins of the British Welfare State. Social welfare in England and Wales, 1800-1945. New York: Palgrave Macmillan.

Malefakis, E. (1970): Agrarian Reform and Peasant Revolution in Spain: Origins of the Civil War. New Haven: Yale University Press. 
Martínez Galarraga, J. (2007): "New Estimates of Regional GDP in Spain, 1860-1930». Document de Treball de la Facultat de Ciències Econòmiques i Empresarials, Col· lecció d'Economia, E07/177.

Ministerio de Trabajo, Comercio e Industria (1927): Estadística de los salarios y jornadas de trabajo referida al periodo 1914-1925, Dirección General de Trabajo y Acción Social. Madrid: Sobrinos de sucesora de M. Minuesa de los Rios, M. Servet.

Murray, J. E. (2007): Origins of American Health Insurance. A History of Industrial Sickness Funds. New Haven y Londres: Yale University Press.

NicolaU, R. (2005): «Población, salud y actividad», en A. Carreras y X. Tafunell (coords.), Estadísticas históricas de España. Bilbao: Fundación BBVA.

Pons Pons, J. (2002): "Las estrategias de crecimiento de las compañías de seguros en España (1900-1940)». Documento de Trabajo 2002/1. Fundación Empresa Pública.

Pons Pons, J. y Pons Brías, M. A. (2010) (coords.): Investigaciones históricas sobre el seguro español. Madrid: Fundación Mapfre.

Pons Pons, J. y Vilar Rodríguez, M. (2011): «Friendly Societies, Commercial Insurance, and the State in Sickness Risk Coverage: The Case of Spain (1880-1940)». International Review of Social History 56 (1), pp. 71-101.

Posada, C. G. (1924): El problema del paro en España. Madrid: Sobrinos de la Sucesora de M. Minuesa de los Ríos.

Prados De La Escosura, L. (2003): El progreso económico de España, 1850-2000. Bilbao: Fundación BBVA.

Rosés, J. R. y SÁnchez-Alonso, B. (2004): «Regional wage convergence in Spain 1850-1930». Explorations in Economic History 41, pp. 404-425.

SÁnchez-Alonso, B. (2000): "European emigration in the late nineteenth century: the paradoxical case of Spain». Economic History Review LIII (2), pp. 309-330.

Sangro Y Ros De Olano, P. (1908). Memoria de los trabajos de la sección en su primer año social (1907) y de la gestión del Consejo Directivo. Publicaciones de la Asociación Internacional para la Protección Legal de los Trabajadores, Sección Española, núm. 4.

Sangro Y Ros De Olano, P. (1911): Memoria de los trabajos de la sección en su cuarto año social (1910) y de la gestión del Consejo Directivo. Publicaciones de la Asociación Internacional para la Protección Legal de los Trabajadores, Sección Española, núm. 18.

Silvestre, J. (2003): «Los determinantes de la protesta obrera en España, 1905-1935: ciclo económico, marco político y organización sindical». Revista de Historia Industrial 24, pp. 51-80.

Silvestre, J. (2007): «Temporary Internal Migrations in Spain, 1860-1930». Social Science History 31 (4), pp. 539-574.

Soto Carmona, A. (1989): El trabajo industrial en la España contemporánea: 1874-1936. Barcelona: Anthropos. 
Van Leeuwen, M. H. D. (1997): «Trade Unions and the Provision of Welfare in the Netherlands, 1910-1960». Economic History Review L (4), pp. 764-791.

Van Leeuwen, M. H. D. (2007): "Historical Welfare Economics in the Nineteenth Century. Mutual Aid and Private Insurance for Burial, Sickness, Old Age, Widowhood, and Unemployment in the Netherlands», en B. Harris y P. Bridgen (eds.), Charity and Mutual Aid in Europe and North America since 1800. New York: Routledge.

Vilar Rodríguez, M. (2010): "La cobertura social a través de los socorros mutuos obreros, 1839-1935. ¿Una alternativa al Estado para afrontar los fallos del mercado?», en J. Pons y J. Silvestre (eds.), Los orígenes del Estado del Bienestar en España, 1900-1945: los seguros de accidentes, vejez, desempleo y enfermedad. Zaragoza: Prensas Universitarias de Zaragoza. 